\title{
Sensitivity of ENSO characteristics to a new interactive flux correction scheme in a coupled GCM
}

\author{
Jürgen Kröger · Fred Kucharski
}

Received: 29 April 2009/ Accepted: 1 February 2010/Published online: 20 February 2010

(C) The Author(s) 2010. This article is published with open access at Springerlink.com

\begin{abstract}
A fast coupled global climate model (CGCM) is used to study the sensitivity of El Niño Southern Oscillation (ENSO) characteristics to a new interactive flux correction scheme. With no flux correction applied our CGCM reveals typical bias in the background state: for instance, the cold tongue in the tropical east Pacific becomes too cold, thus degrading atmospheric sensitivity to variations of sea surface temperature (SST). Sufficient atmospheric sensitivity is essential to ENSO. Our adjustment scheme aims to sustain atmospheric sensitivity by counteracting the SST drift in the model. With reduced bias in the forcing of the atmosphere, the CGCM displays ENSO-type variability that otherwise is absent. The adjustment approach employs a one-way anomaly coupling from the ocean to the atmosphere: heat fluxes seen by the ocean are based on full SST, while heat fluxes seen by the atmosphere are based on anomalies of SST. The latter requires knowledge of the model's climatological SST field, which is accumulated interactively in the spinup phase ("training"). Applying the flux correction already during the training period (by utilizing the evolving SST climatology) is necessary for efficiently reducing the bias. The combination of corrected fluxes seen by the atmosphere and uncorrected fluxes seen by the ocean implies a restoring mechanism that counteracts the
\end{abstract}

\footnotetext{
J. Kröger $(\bowtie)$

Max Planck Institute for Meteorology, Bundesstr. 53,

20146 Hamburg, Germany

e-mail: juergen.kroeger@zmaw.de

F. Kucharski

Earth System Physics, Weather and Climate,

The Abdus Salam International Centre for Theoretical Physics,

Strada Costiera 11, 34014 Trieste, Italy
}

bias and allows for long stable integrations in our CGCM. A suite of sensitivity runs with varying training periods is utilized to study the effect of different levels of bias in the background state on important ENSO properties. Increased duration of training amplifies the coupled sensitivity in our model and leads to stronger amplitudes and longer periods of the Nino3.4 index, increased emphasis of warm events that is reflected in enhanced skewness, and more pronounced teleconnections in the Pacific. Furthermore, with longer training durations we observe a mode switch of ENSO in our model that closely resembles the observed mode switch related to the mid-1970s "climate shift".

Keywords ENSO - Flux correction - Coupled . GCM · Climate shift $\cdot$ Teleconnections

\section{Introduction}

The El Niño Southern Oscillation (ENSO) phenomenon is the most prominent interannual fluctuations in the tropical Pacific (e.g., Philander 1989). The influence of ENSO is not restricted to the tropical Pacific, but is of importance for the global climate. Modeling of ENSO is still a challenge for coupled global climate model (CGCMs), as highlighted by intercomparison projects such as the El Niño Simulation Intercomparison Project (ENSIP, Latif et al. 2001). Continuous improvements in theoretical understanding of ENSO (Kirtman 1997; An and Kang 2000; Fedorov and Philander 2001; Wang et al. 2003, and many others) have not led to a corresponding advance in modeling, even though state-of-the-art CGCMs have improved considerably with respect to previous generations (AchutaRao and Sperber 2006). Although intercomparison 
projects like ENSIP are extremely important, such frameworks in general do not target at isolating the important characteristics of a specific model that lead to improvements in simulating ENSO.

The aim of this paper is to propose a simple means for establishing ENSO variability in one particular CGCM, a method that can easily be extended to other CGCMs that reveal bias in sea surface temperatures (SSTs). Furthermore, we assess the sensitivity of ENSO properties to changes in the background state within the model. These changes are due to different implementations of a new interactive flux correction scheme. The CGCM used is the ICTP AGCM (SPEEDY: Simplified Parameterizations, primitivE Equation DYnamics, in an 8-layer configuration and T30 horizontal resolution; Molteni 2003) coupled in the Indo-Pacific domain to MICOM (version 2.9 with 20 vertical levels; Bleck et al. 1992). Without the flux correction applied, our coupled model exhibits interannual variability that bears little resemblance to the ENSO phenomenon.

Previous modeling studies have shown that within individual CGCMs small changes in the background state can lead to a wide spectrum of ENSO characteristics. The changes may be induced by flux correction alone or by targeted perturbations of the model physics (Toniazzo et al. 2008). Relatively simple adjustment approaches, such as superimposing an empirical constant heat flux, can lead in some models to significant improvements of ENSO properties and, consequently, of predictive skill (Manganello and Huang 2009). It is not guaranteed for every CGCM, however, that flux correction improves the representation of ENSO. For example, Spencer et al. (2007) systematically studied how details of the adjustment procedure, such as the choice of the region where the flux correction is applied, lead to ENSO modes in their CGCM that are either too weak or too strong and frequent. The authors concluded that none of their attempts helped to improve ENSO representation in their model.

In this study we show how systematic changes in the background state of our coupled model (1) enable ENSOtype variability in the system and (2) lead to drastic changes in ENSO properties that span almost the entire range of variation found in intercomparison studies (Latif et al. 2001). Compared to a multi-model effort like ENSIP, our single model approach allows for a more detailed understanding of the reasons for changes of ENSO properties. The paper is organized as follows: in Sect. 2, the model and flux correction strategy are introduced. The climatological properties of all experiments are presented and compared to observations in Sect. 3. In Sect. 4, we discuss local characteristics, teleconnections, non-linearity and formation of ENSO in our experiments. A summary and discussion concludes the paper in Sect. 5.
2 Model and methodology of interactive flux correction

\subsection{Configuration}

The coupled general circulation model (GCM) that we use in this study, also referred to as the CGCM, consists of the fast ICTP atmospheric GCM (AGCM) SPEEDY (Molteni 2003), that is applied here with a vertical resolution of eight layers and a truncation at the wavenumber 30 (for more details see Kucharski et al. 2006; Bracco et al. 2004, for a 7-layer version), and the ocean GCM (OGCM) MICOM (Miami Isopycnic Coordinate Ocean Model, version 2.9, see Bleck et al. 1992). The ocean model is configured for the Indo-Pacific region $\left(30^{\circ} \mathrm{E}-67^{\circ} \mathrm{W}, 30^{\circ} \mathrm{S}-63^{\circ} \mathrm{N}\right)$ with 20 density layers in the vertical, a constant longitudinal resolution of $2^{\circ}$, and a latitudinal resolution of $1 / 2^{\circ}$ on the equator that gradually increases to $1^{\circ}$ at the southern and $2^{\circ}$ at the northern boundary. At the lateral boundaries in the north and south the thermodynamic properties of MICOM are restored towards observed climatological values from Levitus et al. (1994). The Levitus et al. (1994) data set is also used to initialize the ocean model.

Inside the Indo-Pacific region, MICOM provides the necessary SST to force the atmosphere. Outside of the ocean model's domain, SPEEDY is driven by observational estimates of climatological surface temperatures from the European Centre for Medium-Range Weather Forecasts' re-analysis (ERA; for a further description of this and all other climatological fields and the basic parameterizations used in SPEEDY see Molteni 2003, and references therein). The coupling of the model components is provided by a distributed coupler from the Los Alamos National Laboratory. More details about the CGCM can be found in the technical report of Hazeleger et al. (2003). The CGCM has been successfully used in different configurations for studies in the South and tropical Atlantic (Haarsma et al. 2005; Hazeleger and Haarsma 2005) and in the Indo-Pacific region (Bracco et al. 2005, 2006; Kucharski et al. 2007, 2008).

\subsection{Methodology}

In Fig. 1 the difference between the long term mean SST (after a 100 years of integration) in our uncorrected reference run (NO_COR) and the observed ocean climatology from ERA (cf. Sect. 2.1, hereafter referred to as $\mathrm{SST}_{\text {CLIM oBS }}$ ) is shown for the Pacific sector. The SST reveals a cold bias over almost the entire tropical and subtropical region with a zonally extended maximum in magnitude of more than $4^{\circ} \mathrm{C}$ around the equator and the dateline, and a secondary maximum of $2^{\circ} \mathrm{C}$ located north of $20^{\circ} \mathrm{N}$ and west of the dateline. Everywhere else the modeled Pacific appears too warm, with pronounced biases in 


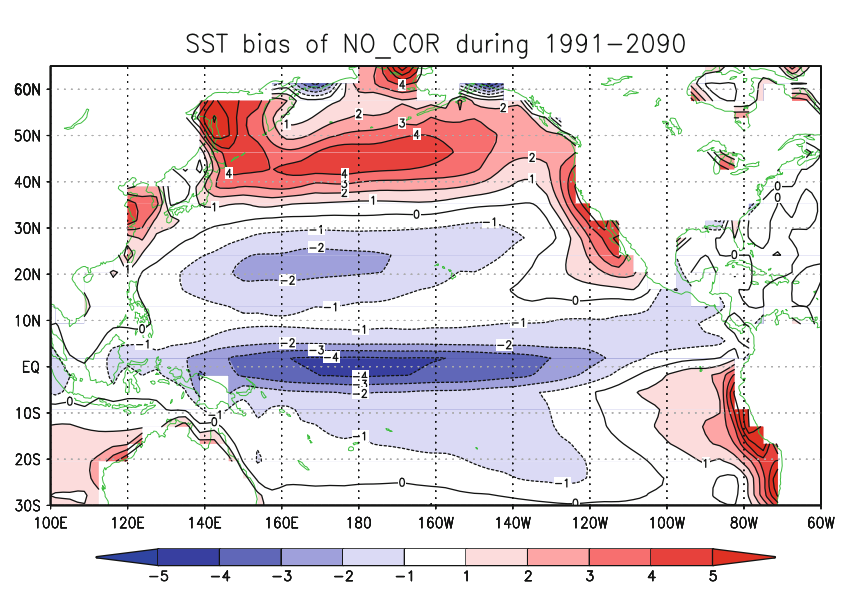

Fig. 1 SST bias in the uncorrected run (NO_COR): difference of observed climatology (ERA) and model's ocean climate accumulated over 100 years $(1991-2090)\left({ }^{\circ} \mathrm{C}\right)$

the subpolar North Pacific north of $35^{\circ} \mathrm{N}$ and near North and South America between $30^{\circ} \mathrm{S}-0^{\circ}$ and $20^{\circ} \mathrm{N}-50^{\circ} \mathrm{N}$ and with maximum values exceeding $4^{\circ} \mathrm{C}$. The drift in the climate state is a common problem in coupled GCMs that are not subject to a correction of their fluxes at the oceanatmosphere interface, as, for instance, was pointed out by the Coupled Model Intercomparison Project CMIP1 (Lambert and Boer 2001). Especially in the tropical Pacific, at the heart of ENSO, a cold bias in SST with the same order of magnitude as the one in our uncorrected run is a typical characteristic of most coupled models without flux correction (Latif et al. 2001; Davey et al. 2002). Such an unrealistic basic state is believed to be related to a split Intertropical Convergence Zone (ITCZ) over the western Pacific, as was identified by AchutaRao and Sperber (2006) in the recent generation of models that contributed to the Intergovernmental Panel on Climate Change Fourth Assessment Report (IPCC AR4, see IPCC 2007).

In our new interactive adjustment approach we employ a form of anomaly coupling (e.g. Kirtman 2003; Ji et al. 1998). As in Ji et al. (1998), a one-way anomaly coupling is used, but, in contrast to Ji et al. (1998), we apply the anomaly coupling from the ocean to the atmosphere, that is, we only correct heat fluxes that are seen by the atmosphere. In our adjustment procedure, the correction of the heat fluxes is solely based on correcting SST, with all other related model variables remaining unmodified. For this purpose, we need to know the model's SST anomalies (SSTAs). In order to be able to extract SSTAs from the full SSTs, we need to define the model's climatological SST field. The model's climatology is calculated iteratively in the spin-up phase of each experiment. Therefore, in our approach, the definition of the model's climatology does not require any separate runs of the coupled system or its oceanic component. The obtained SSTAs, superimposed on an observed SST climatology, are then used for the calculation of the corrected heat fluxes. The term interactive in our approach relates to the interdependency of the corrected fluxes and the continuously evolving model climatology during spin-up, as explained in detail below.

Since we apply the anomaly coupling solely in one direction, we only partly correct the heat fluxes by correcting SST as follows: every time the model exchanges information between ocean and atmosphere (once per day in our runs), we calculate the heat fluxes twice to separate between fluxes seen by the atmosphere and those seen by the ocean. The calculation of the fluxes into the ocean is based on the actual, unaltered SST. In this case no correction is applied. The calculation of the fluxes into the atmosphere, on the other hand, involves adjustment. In that case we only consider the anomalies of the actual SST and superimpose them onto the same observed climatology that is used to force the atmosphere outside the coupled region $\left(\mathrm{SSTA}+\mathrm{SST}_{\mathrm{CLIM} \_ \text {oBS }}\right)$. We adopt this one-way approach because, as our results will show, not only is the bias in the model's SST substantially reduced, but also the coupled system establishes a more realistic ENSO. The latter happens because the atmosphere is not directly subjected to the drift in the ocean's cold tongue towards lower temperatures which, otherwise, significantly reduces its sensitivity to the SST variability. Furthermore, as preliminary experiments with our coupled model have shown, only when applying the anomaly coupling from the ocean to the atmosphere, the adjustment procedure implies a restoring mechanism that is sufficient to counteract the bias. Given this particular coupling strategy, the flux correction, by providing enhanced (reduced) net heat flux into the ocean when its background state tends to drift towards colder (warmer) temperatures, is able to moderate and eventually stop the drift in the model's SST that allows for long stable integrations.

In the following we explain how we initialize the adjustment procedure in the early spin-up phase of the coupled system. The flux adjustment uses anomalies of the model's SST. The calculation of the anomalies requires knowledge of the model's SST climatology $\left(\mathrm{SST}_{\text {CLIM_MODEL }}\right)$. We obtain $\mathrm{SST}_{\text {CLIM_MODEL }}$ by iterating SST when spinning up the coupled model ("training"). This training poses several strategic issues: how long should the training be, and to what extent should the adjustment procedure be involved in the training. Regarding the latter, one strategy could be a complete separation, that is, we do not start the flux adjustment before the training is finished. Or we could launch both training and adjustment at the beginning of the spin-up, with the flux correction procedure either gradually increasing during training or operating to the full extent. A first set of experiments has shown that it is important to apply a full adjustment to the model's SST as soon as possible in order 
to achieve a considerable reduction in the cold bias of the equatorial cold tongue. Starting the training with no or with only a smoothly increasing correction leads to a similar drop in mean equatorial temperatures as in the uncorrected run (not shown).

As a consequence, all sensitivity experiments discussed in this paper apply the full adjustment based on SSTA in the early spin-up phase of the coupled system, namely two years after starting the runs from an initial motionless state. In the first two years, before starting the adjustment, we force the atmosphere over the Indo-Pacific region, like everywhere else, with fluxes that are solely based on the prescribed climatology ( $\left.\mathrm{SST}_{\text {CLIM_OBS }}\right)$. In year two, we begin to calculate the ocean's mean state $\left(\mathrm{SST}_{\text {CLIM_MODEL }}\right)$, which allows us to calculate SSTA from year three onward. The focus of our study is on the sensitivity of the background state and the accompanying ENSO characteristics in the model with respect to the length of the training. Therefore, we performed a suite of experiments with 10, 20, and 30 years of training (TRAIN_10, TRAIN_20, TRAIN_30). Note that, in each particular experiment, SST CLIM_MODEL $_{\text {is }}$ is not further modified at the end of the training period but is kept at its respective value. In addition, we set up a continuously trained run (TRAIN_CONT) that gives insight into the convergent nature of the bias in the system. However, TRAIN_CONT is not further used for the investigation of ENSO characteristics since the ongoing non-stationary adjustment in this run by itself might be a spurious source of variability. A systematic investigation of the convergent behavior of the ocean's reference state in coupled systems with respect to different approaches in accumulating SST is given by Macias et al. (1999). Note that NO_COR, TRAIN_10, TRAIN_20, TRAIN_30 are not subject to external climate forcing, that is, we do not impose a transient forcing function onto the system like, for instance, a prescribed increase in $\mathrm{CO}_{2}$ or other greenhouse gases in a global warming scenario. All our experiments start in January 1991. Since we do not impose a forcing, the year is somewhat arbitrary but relates to the fact that all climatological fields used by the AGCM are averages from 1981 to 1990 (Molteni 2003). All analysis of variability is based on monthly mean time series, excluding the training period and with the climatological annual cycle removed.

\section{Model climate and ENSO variability}

\subsection{SST climatology and drift}

The differences between SST $_{\text {CLIM_OBS }}$ and SST $_{\text {CLIM_MODEL }}$ in experiments TRAIN_10, TRAIN_20, and TRAIN_30 are shown in Fig. 2 (left column). Note that $\mathrm{SST}_{\text {CLIM_MODEL }}$ is defined by the mean (accumulated) SST at the end of training after integrating TRAIN_10, TRAIN_20, and TRAIN_30 for 10, 20, and 30 years, respectively. Since we stop calculating the ocean model's SST at the end of training (we "freeze in" SST $_{\text {CLIM_MODEL }}$ ), the differences in Fig. 2 (left column) represent exactly the adjustment in each run that is applied to the ocean's background state in the post-training period. A cooling in the equatorial band and a warming in the subpolar North Pacific and off the Americas are apparent in all three runs and illustrate the same tendencies seen in the uncorrected experiment NO_COR (Fig. 1). But there is already one important difference present in all corrected runs: the center of the maximum equatorial cold bias has been shifted eastward by about $60^{\circ}$ and is now located around $120^{\circ} \mathrm{W}$. In the cold tongue region, the peak value of the cold bias moderately increases over the course of the training from about $2^{\circ} \mathrm{C}$ after 10 years to more than $3^{\circ} \mathrm{C}$ after 30 years, whereas it is more difficult to detect a trend in the regions that are subject to warming.

To provide a better quantitative estimate of the effect of the adjustment with reference to the uncorrected run NO_COR, we look at the particular SST biases after integrating the experiments for 100 years (Fig. 2, right column). All corrected runs reveal a coherent pattern with overall more confined and less pronounced structures than in NO_COR (cf. Fig. 1). In particular, the local extrema along the dateline are remarkably reduced to absolute values between 1 and $2^{\circ} \mathrm{C}$ around $45^{\circ} \mathrm{N}$ and on the equator. The broad patch at $20^{\circ} \mathrm{N}$ has completely vanished. The equatorial cold bias still exceeds $4^{\circ} \mathrm{C}$ in TRAIN_10 and $3^{\circ} \mathrm{C}$ in all other corrected runs, but, as noted above, is more concentrated in the eastern half of the basin around $120^{\circ} \mathrm{W}$. Note the similarity between accumulated SST after 30 years of training (Fig. 2c) and after 70 more years of integration (Fig. 2f) in TRAIN_30, which is strongly indicative of the convergent nature of the method. The similarity to the accumulated SST after 100 years of training in TRAIN_CONT corroborates the convergent behavior (not shown).

It is instructive to compute the time-mean equatorial temperature distribution as in Latif et al. (2001), which is depicted in Fig. 3 for both the observations ( $\mathrm{SST}_{\text {CLIM_OBS }}$ ) and the model results. Unlike before, this time we consider the SSTs that are used to compute the surface fluxes seen by the atmosphere $\left(\mathrm{SST}_{\text {CLIM }}\right.$ oBs + SSTA) and we choose an averaging window of 100 years after the respective training period (model years 2050-2150). Since the model runs still exhibit minor drift in their post-training period (which is of varying extent in the particular experiments, Fig. 2), these temperatures are different from the prescribed SST climatology (SST CLIM_oBS $_{\text {) }}$ used in the flux correction and constitute the particular background states 
(a) SST bias of TRAIN_10 during 1991-2000

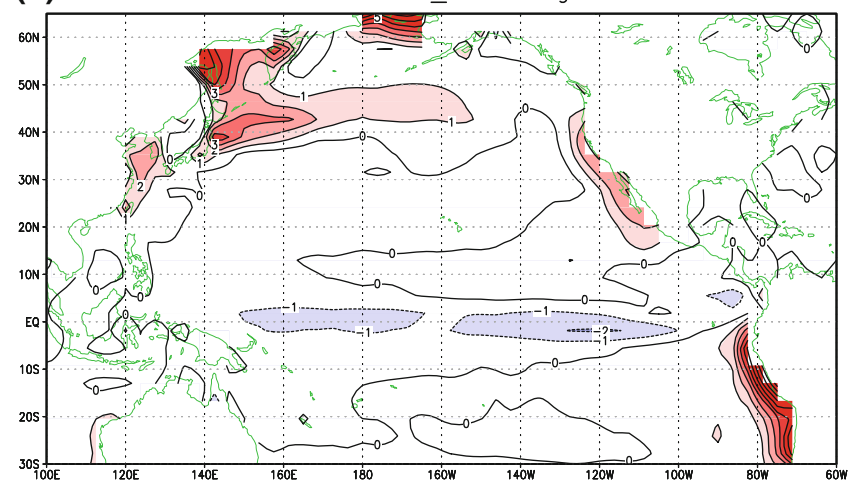

(b)
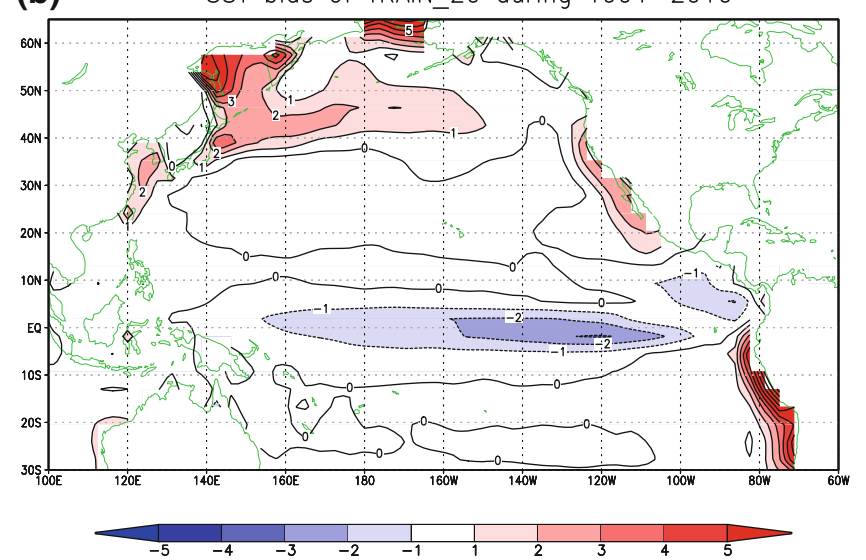

(c)
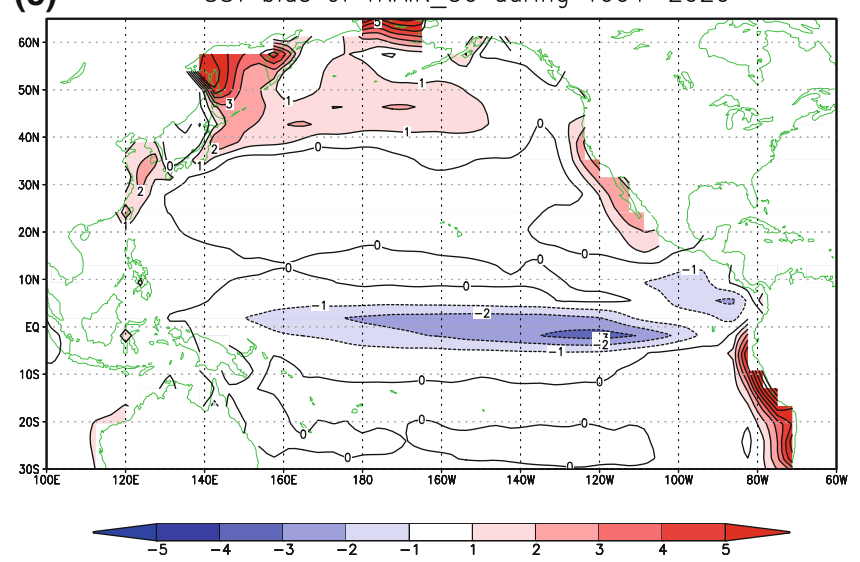

Fig. 2 SST biases in the corrected runs: (a, d) TRAIN_10, (b, e) TRAIN_20 and (c, f) TRAIN_30 with 10, 20 and 30 years of training, respectively. Difference of observed climatology (ERA) and model's

seen by the atmosphere. Our flux-corrected runs reveal a much reduced drift as was intended. TRAIN_10 is still $2^{\circ} \mathrm{C}$ too cold in the eastern Pacific and about $1.5^{\circ} \mathrm{C}$ too warm in the west Pacific (yellow line). These errors are further reduced in TRAIN_20 (red line) and TRAIN_30 (blue line), with the temperatures in TRAIN_30 being even slightly too warm in the central and eastern Pacific. (d) SST bias of TRAIN_10 during 1991-2090
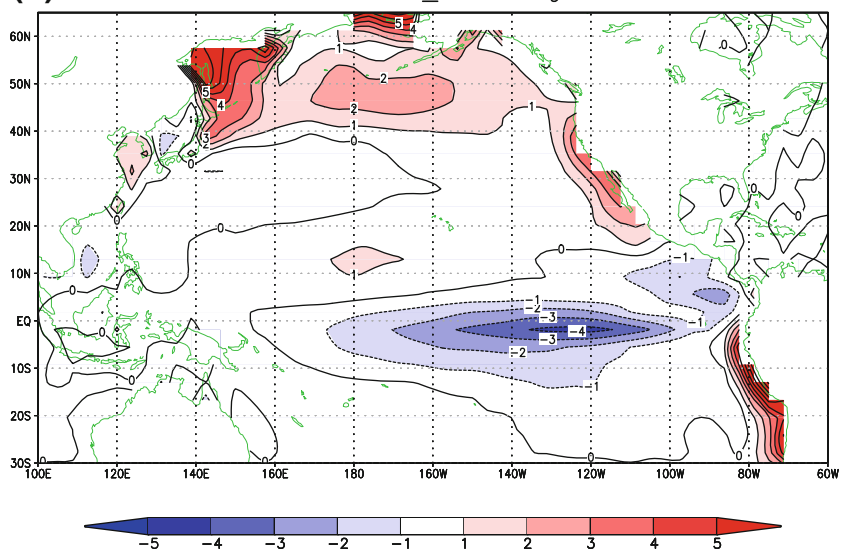

(e)

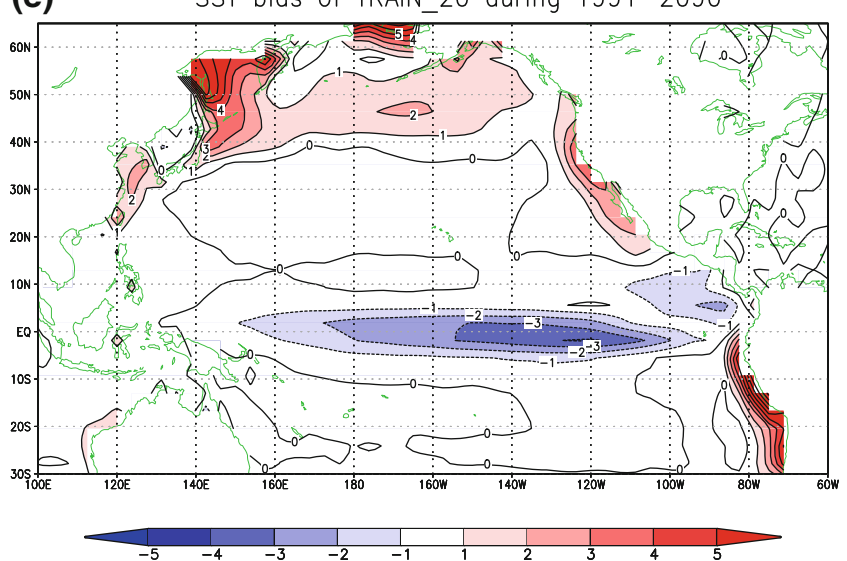

(f)

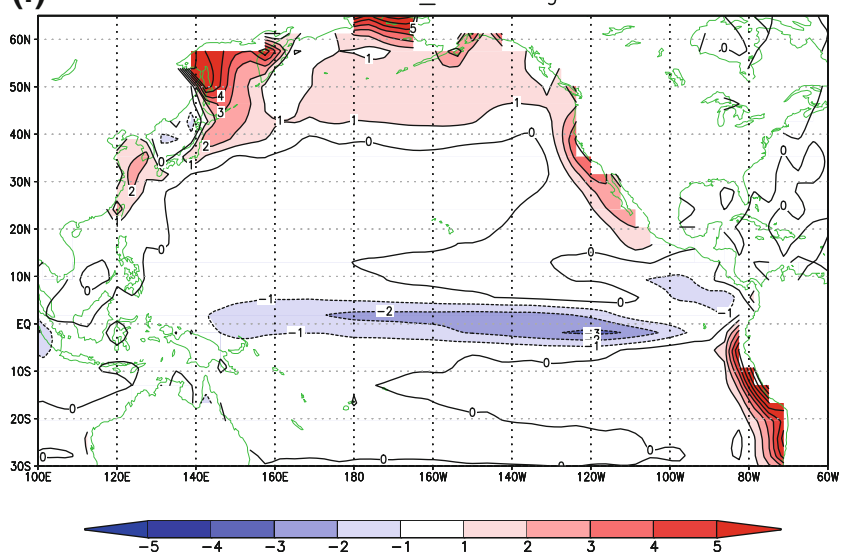

ocean climate accumulated over (left column) the respective period of training and (right column) 100 years (1991-2090) $\left({ }^{\circ} \mathrm{C}\right)$

\subsection{Precipitation climatology}

In Fig. 4, we compare simulated mean states of rainfall in boreal winter (December-January-February, hereafter DJF, 2050 to 2150) with the DJF climatology of the Climate Prediction Center Merged Analysis of Precipitation (CMAP) dataset from Xie and Arkin (1997) (Fig. 4, upper 


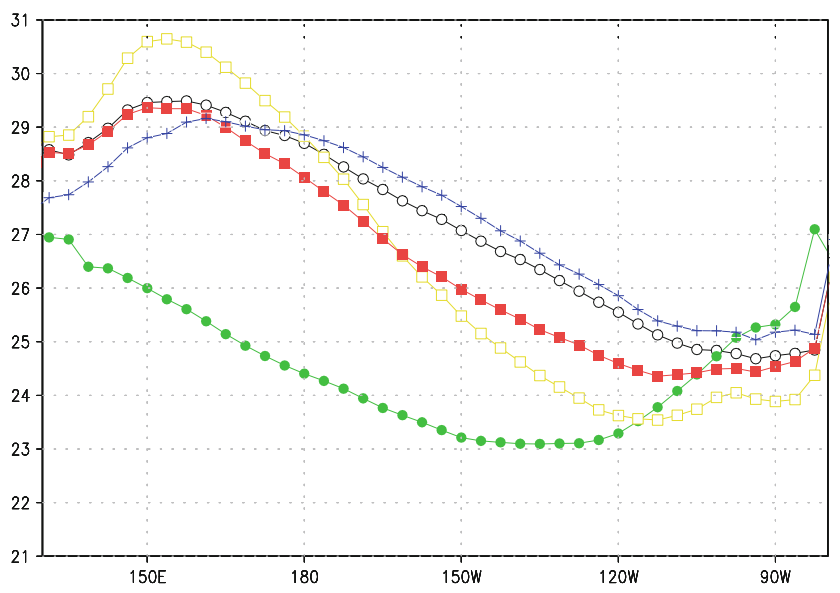

Fig. 3 Equatorial SST as seen by the atmosphere (SST $\mathrm{SLIM}_{-} \mathrm{OBS}+$ SSTA, averaged between $2^{\circ} \mathrm{S}$ to $2^{\circ} \mathrm{N}$ and model years 2050-2150): HadISST (years 1981-1990, black line), NO_COR (green), TRAIN_10 (yellow), TRAIN_20 (red), and TRAIN_30 (blue), $\left({ }^{\circ} \mathrm{C}\right)$

left) and with DJF climatology of a SPEEDY stand-alone run forced with the Met Office Hadley Centre's sea ice and SST data set (HadISST, Rayner et al. 2003) (Fig. 4, lower right). With no flux adjustment applied (NO_COR), the South Pacific Convergence Zone (SPCZ) in the model degenerates into a southern Intertropical Convergence Zone (ITCZ, with maximum values of precipitation exceeding $16 \mathrm{~mm} /$ day) that transects the dry area off South America by penetrating all the way into the east Pacific basin along $10-15^{\circ} \mathrm{S}$ (Fig. 4, upper right). The unrealistic "double ITCZ" structure is associated with an equally elongated band of no precipitation on the equator, which has to be understood as a direct consequence of the pronounced equatorial cold bias in NO_COR (Fig. 1). In addition, north of the northern ITCZ, the band of local minimum values around $20^{\circ} \mathrm{N}$ is much too broad and extends too far to the west in comparison to the observations, and, again, coincides with too cold climatological SSTs in the uncorrected model. In the region of the Kuroshio current, on the other hand, where the model's ocean temperature is too warm, the precipitation with values between 8 and $12 \mathrm{~mm} /$ day is about twice as much as in the CMAP data set.

The application of flux correction, overall, leads to improved patterns and magnitudes of precipitation over the Pacific Ocean (Fig. 4, center and lower left). In all adjusted runs, the SPCZ no longer transforms into a pronounced southern ITCZ that penetrates into the dry area in the eastern South Pacific, and, in line with the forced atmosphere only experiment (SPEEDY stand-alone, Fig. 4, lower right), reveals the same intensity as the SPCZ in CMAP ( $>12 \mathrm{~mm} /$ day). In TRAIN_10, the area of no precipitation still extends too far to the west, almost reaching the dateline on the equator (Fig. 4, center left), whereas in the other corrected runs it resembles the shape of the observed dry area in the eastern South Pacific reasonably well (see TRAIN_20 and TRAIN_30 in Fig. 4, center right, and lower left, respectively). Another spurious feature that only occurs in TRAIN_10 is the local maximum in precipitation with highest values of more than $16 \mathrm{~mm} /$ day located around $160^{\circ} \mathrm{E}$ and $5^{\circ} \mathrm{N}$, of which no obvious correlation can be found in the climatological SST (Fig. 2d). The experiments with training periods of 20 years and longer (TRAIN_20, TRAIN_30, also TRAIN_CONT, not shown) establish similar winter climatologies in rainfall that are in good accordance with the observations. All experiments overestimate precipitation over South America, with maximum values exceeding $16 \mathrm{~mm} /$ day east of the Peruvian Andes. TRAIN_30 and SPEEDY stand-alone reveal another local maximum at the eastern tip of the marine ITCZ $\left(10 \mathrm{~mm} /\right.$ day around $100-90^{\circ} \mathrm{W}$ and $\left.5-10^{\circ} \mathrm{N}\right)$ that is absent in CMAP.

\section{ENSO variability, teleconnections, and formation characteristics}

\subsection{Nino3.4 index}

Figure 5 is a compilation of the interannual to multi-decadal SST variability in the Nino3.4 region (Nino3.4 index) in experiments NO_COR, TRAIN_10, TRAIN_20, and TRAIN_30. The Nino3.4 index is a spatial average of SSTA from $170^{\circ}$ to $120^{\circ} \mathrm{W}$ and $5^{\circ} \mathrm{S}$ to $5^{\circ} \mathrm{N}$; we have removed the climatological cycle and show the first 200 years of the integrations. For comparison, the Nino3.4 index from HadISST is included in Fig. 5 (1871-2000). Note that the model time series shown in Fig. 5 go back to the start of the experiments (model year 1991) and, therefore, include the training periods in the corrected runs. However, calculations of standard deviation (SD), frequency and skewness (summarized in Table 1) are based on the Nino3.4 index after the training (model years 20712200). The severe drop in mean equatorial SST in NO_COR, with its local maximum exceeding $4^{\circ} \mathrm{C}$ slightly west of the Nino3.4 area (cf. Fig. 1), is also reflected in the Nino3.4 time series (Fig. 5a). In the first two decades the Nino3.4 index reveals a linear downward trend of about $4^{\circ} \mathrm{C}$ followed by a smooth warming of less than $1^{\circ} \mathrm{C}$ within the subsequent 180 years. The cooling period of about 20 years is indicative of the thermodynamic adjustment time scale in the upper layers in the tropics in our coupled system. Once locked into the cold state, NO_COR seems to be unable to establish a significant ENSO variability, although the SD of the Nino3.4 index still reaches a value of $0.68^{\circ} \mathrm{C}$. For comparison, the SD of the Nino3.4 index from HadISST (Fig. 5e), computed for the period 

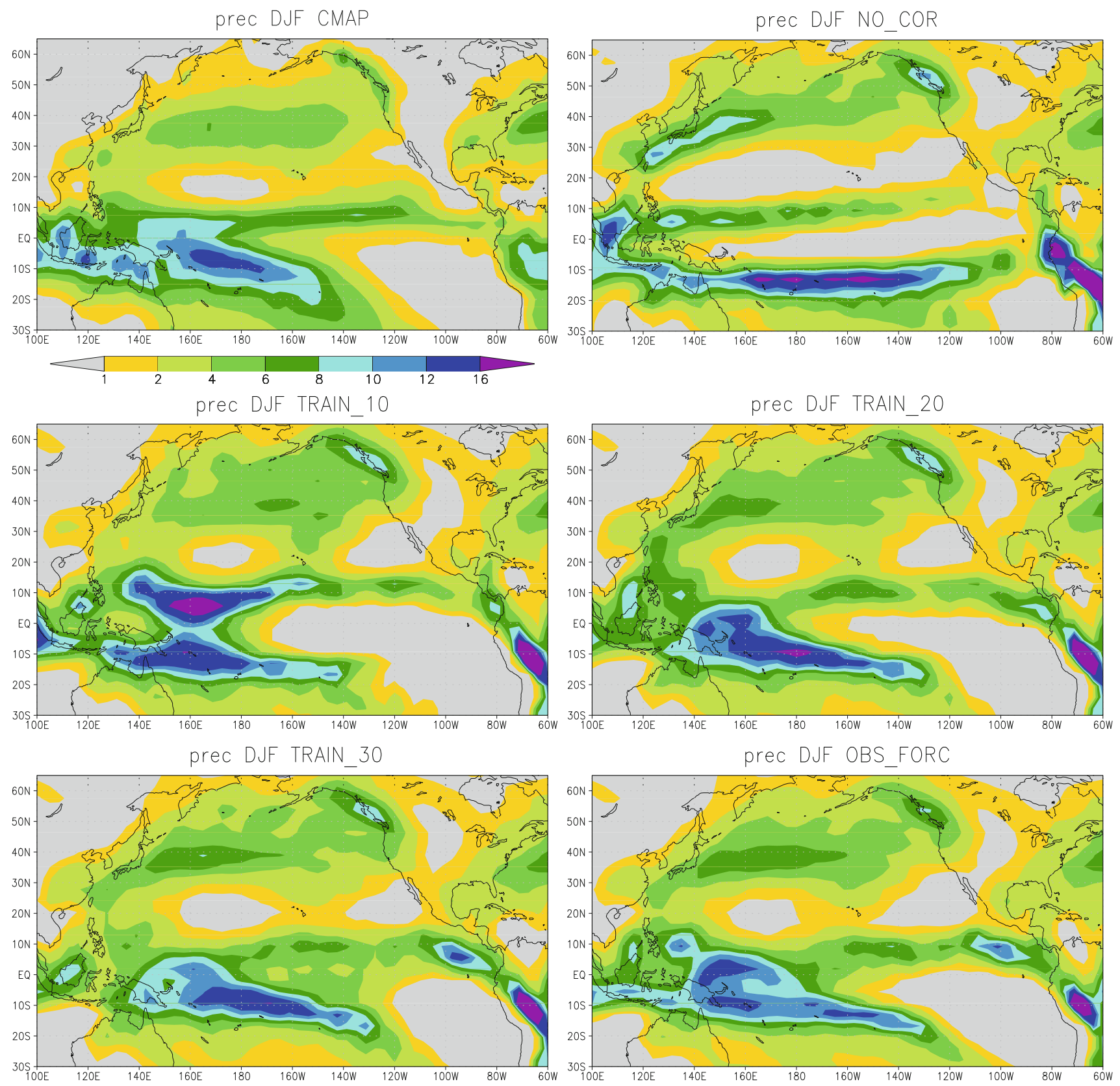

Fig. 4 Precipitation in winter (Dec-Jan-Feb) (mm/day): (upper, left) observed climatology CMAP (1980-1998), model climatologies (2050-2150) in (upper, right) NO_COR, (center, left) TRAIN_10,

(center, right) TRAIN_20, (lower, left) TRAIN_30, (lower, right) SPEEDY stand-alone forced with HadISST (1950-2002)

$1871-2000$, is $0.74^{\circ} \mathrm{C}\left(0.81^{\circ} \mathrm{C}\right.$ if only considering the second half of the twentieth century).

The corrected runs, in contrast to NO_COR, show vigorous fluctuations, with quite different characteristics regarding frequencies and amplitudes. After the spin-up, in TRAIN_10, the Nino3.4 signal is dominated by interannual variability with moderate amplitudes $\left[O\left(1-2{ }^{\circ} \mathrm{C}\right)\right]$ that are sporadically superseded by warm peak events with more than $3^{\circ} \mathrm{C}$ (SD $1.08^{\circ} \mathrm{C}$, Fig. 5 b).

In TRAIN_20, a much higher contrast is revealed between the rather low-energetic and high-frequent interannual variability $\left[O\left(1^{\circ} \mathrm{C}\right)\right]$ and strong warm events with amplitudes of $5-6^{\circ} \mathrm{C}\left(\mathrm{SD} 1.28^{\circ} \mathrm{C}\right)$, which appear only occasionally with long decadal to multi-decadal gaps between the warm events (Fig. 5c). In TRAIN_30, we find a similar low-energetic interannual variability that is superimposed by strong warm events of $O\left(5-6^{\circ} \mathrm{C}\right)$ (SD $1.88^{\circ} \mathrm{C}$ ), but, in contrast to TRAIN_20, the appearance of 
(a)

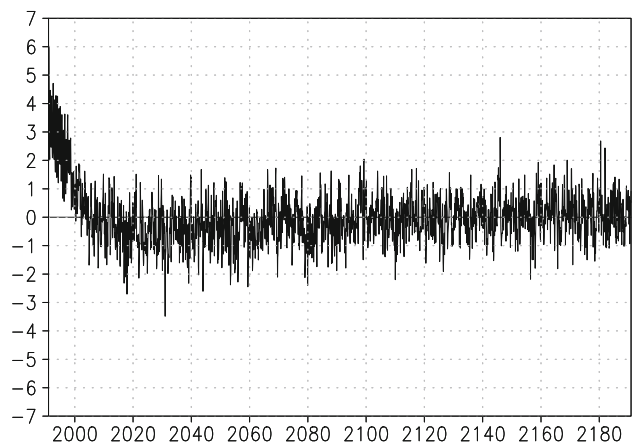

(c)

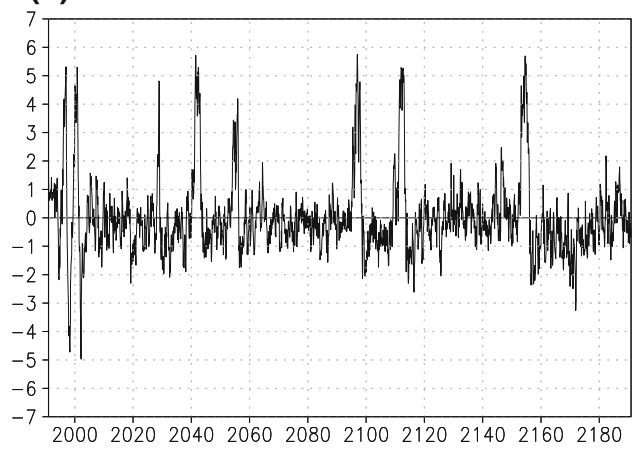

(b)

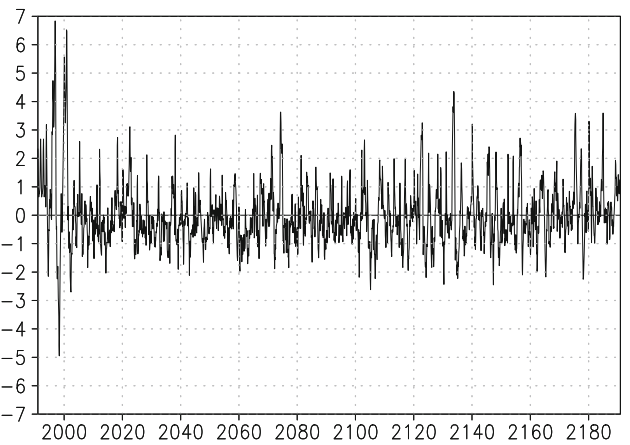

(d)

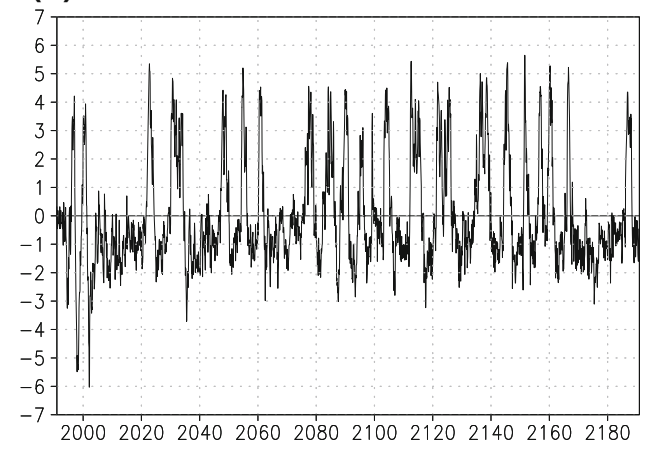

(e)

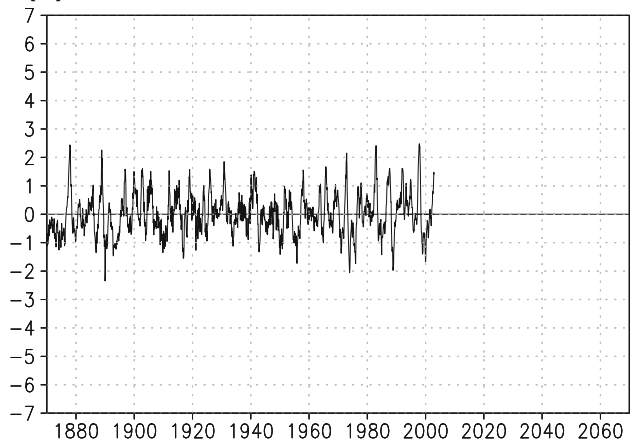

Fig. 5 Comparison of the modeled Nino3.4 index (spatial average of SSTA from $170^{\circ}$ to $120^{\circ} \mathrm{W}$ and $5^{\circ} \mathrm{S}$ to $5^{\circ} \mathrm{N}$ ) for the model years $1991-2190$ $\left({ }^{\circ} \mathrm{C}\right)$ : a NO_COR, b TRAIN_10, c TRAIN_20, d TRAIN_30, e HadISST (1871-2002)

the warm events is much more frequent and less intermittent (Fig. 5d). The cumulative appearance of massive warm ENSO events in the corrected runs with a lack of notable cold counterparts in between is indicative of an enhanced skewness in the ENSO signal compared to NO_COR. We will discuss the skewness in our model in Sect. 4.3.

It is instructive to consider the power spectra and autocorrelation functions for the HadISST data and for the different model results (Fig. 6). Both the power spectrum and the autocorrelation point to the prevailing variability of SST in the Nino3.4 region. The autocorrelation function provides additional information about the characteristic of the SST variability, therefore we refer mainly to Fig. 6 (lower) for the discussion. For the HadISST (black line; using the years 1950-2002), the autocorrelation clearly suggests an oscillatory behavior with a period of about 4-5 years. The autocorrelation for NO_COR (green line) reveals an e-folding time of about 6 months and no indication of an oscillatory behavior at all. On the other hand, all flux-corrected runs show oscillatory behavior with periods ranging from 2 to 3 years in TRAIN_10 (yellow line) and 6 to 8 years (to about a decade when looking at the power spectrum) in case of TRAIN_20 (red line) and TRAIN_30 (blue line). Thus, although the uncorrected CGCM reveals interannual SST variability on the equator, it seems to lack an ENSO-like oscillatory behavior. This is substantially improved by the flux correction. In Sect. 4.4, 

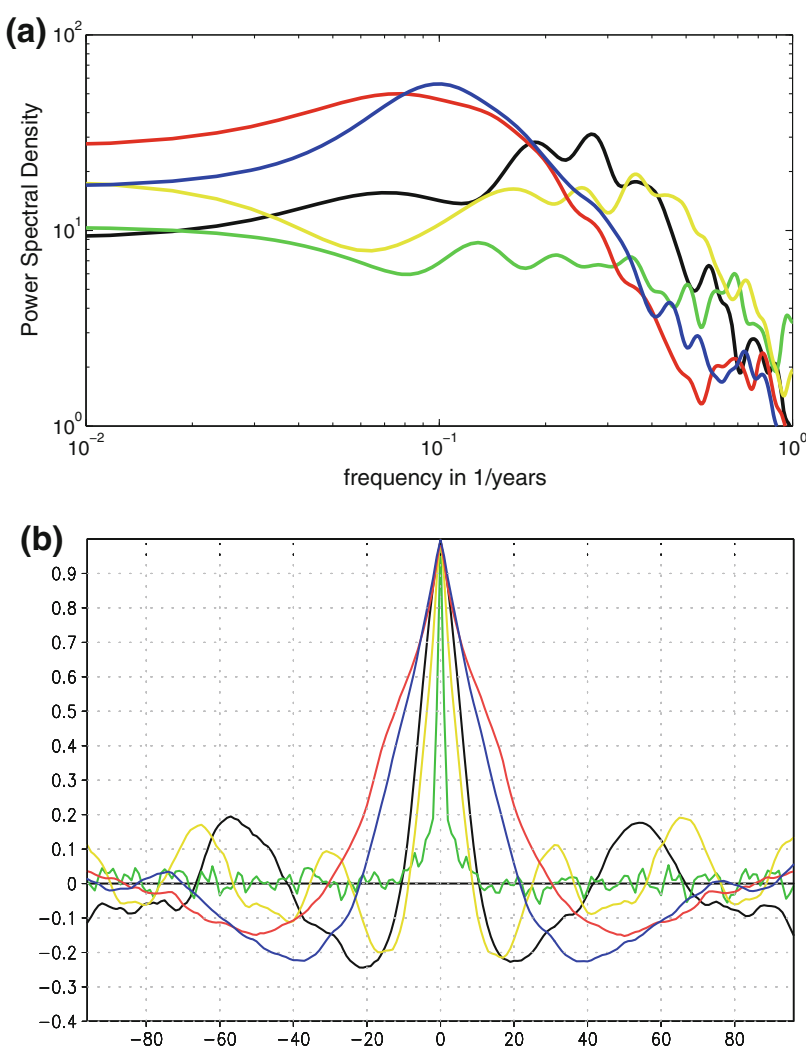

Fig. 6 Power spectrum (upper) and autocorrelation function (lower) for the Nino3.4 index (model years 2050-2150): HadISST (19502002, black line), NO_COR (green), TRAIN_10 (yellow), TRAIN_20 (red) and TRAIN_30 (blue)

we will come back to the differing ENSO time-scales in our corrected runs, that is, relatively high frequency in TRAIN_10 and low frequency in TRAIN_20 and TRAIN_30 as compared to the observations.

Another important issue, as well discussed by Latif et al. (2001), is the phase locking of the Nino3.4 variability with the seasonal cycle. Figure 7 presents the Nino3.4 SD (in ${ }^{\circ} \mathrm{C}$ ) for every month. In the HadISST data (black line), the SD reveals a minimum in spring and a maximum in winter. As demonstrated by Latif et al. (2001), 15 out of 23 models in the ENSIP intercomparison did not show any phase locking of ENSO with the seasonal cycle, and in only four cases did the phase locking agree with observations. The phase locking also turns out to differ in our experiments. The uncorrected run (green line) reveals maximum variability in winter and in late spring/early summer, while TRAIN_10 (yellow line) shows a maximum SD in spring. On the other hand, TRAIN_20 (red line) and TRAIN_30 (blue line) simulate the spring minimum and winter maximum more or less correctly, These two experiments, however, also have a tendency for an unrealistic secondary maximum at the end of summer.

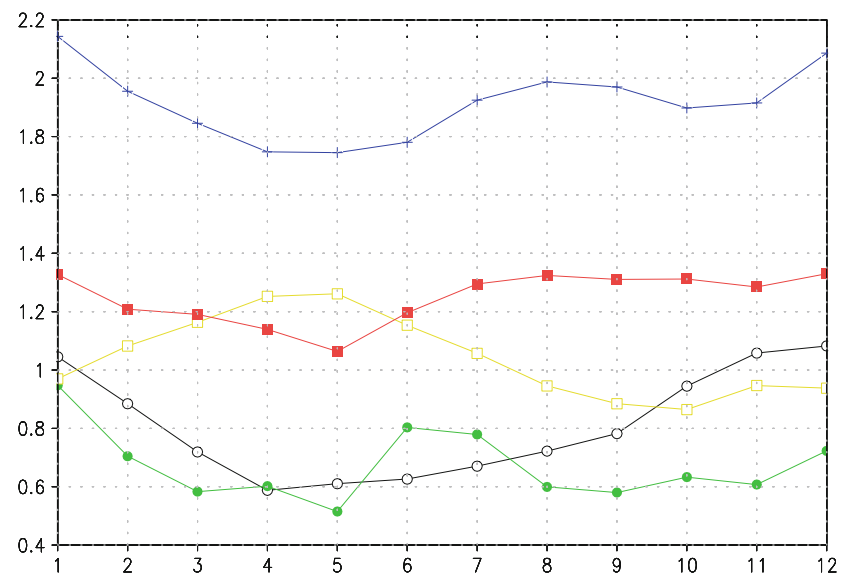

Fig. 7 Standard deviation of the Nino3.4 index for all months of the year (model years 2050-2150): HadISST (1950-2002, black), NO_COR (green), TRAIN_10 (yellow), TRAIN_20 (red) and TRAIN_30 (blue) $\left({ }^{\circ} \mathrm{C}\right)$

\subsection{Nino3.4 regressions}

To better understand why the flux correction changes the properties of the SST variability in the tropical Pacific so drastically, we look at regression maps of selected fields onto the Nino3.4 index (here again we present results for boreal winter, DJF). Please note that, unless stated otherwise, all regression maps show the covariance of the normalized Nino index (by the SD) with the respective variable of interest. In Fig. 8 the regression for surface temperature is shown (for the comparison to observations again we use the years 1950-2002 of the HadISST data set, see Fig. 8a). In the model results an overall progressive increase in amplitude can be found as we go from NO_COR (Fig. 8b) to TRAIN_30 (Fig. 8e). More interestingly, all the flux corrected runs reveal quite realistic teleconnections with the equatorial west Pacific and extratropical North Pacific. In detail, we find the position of the maximum warm amplitude being more or less correct in TRAIN_20 and TRAIN_30, whereas it is located somewhat too far in the central equatorial Pacific in TRAIN_10. A principal component analysis applied to the tropical Pacific SSTs gives about the same spatial patterns as those derived from the simple regression analysis.

The regression of precipitation and $925 \mathrm{hPa}$ wind onto the Nino3.4 index in Fig. 9 is probably the key to understand why the flux corrected runs exhibit more realistic ENSO properties. The reason is that these fields are direct indicators of the extent of connection between the ocean and the atmosphere. As an observational estimate, we take $925 \mathrm{hPa}$ wind vectors from the National Centers for Environmental Prediction (NCEP; Kalnay et al. 1996) Reanalysis and the precipitation data from CMAP (available only after 1979) and regress both onto the HadISST 

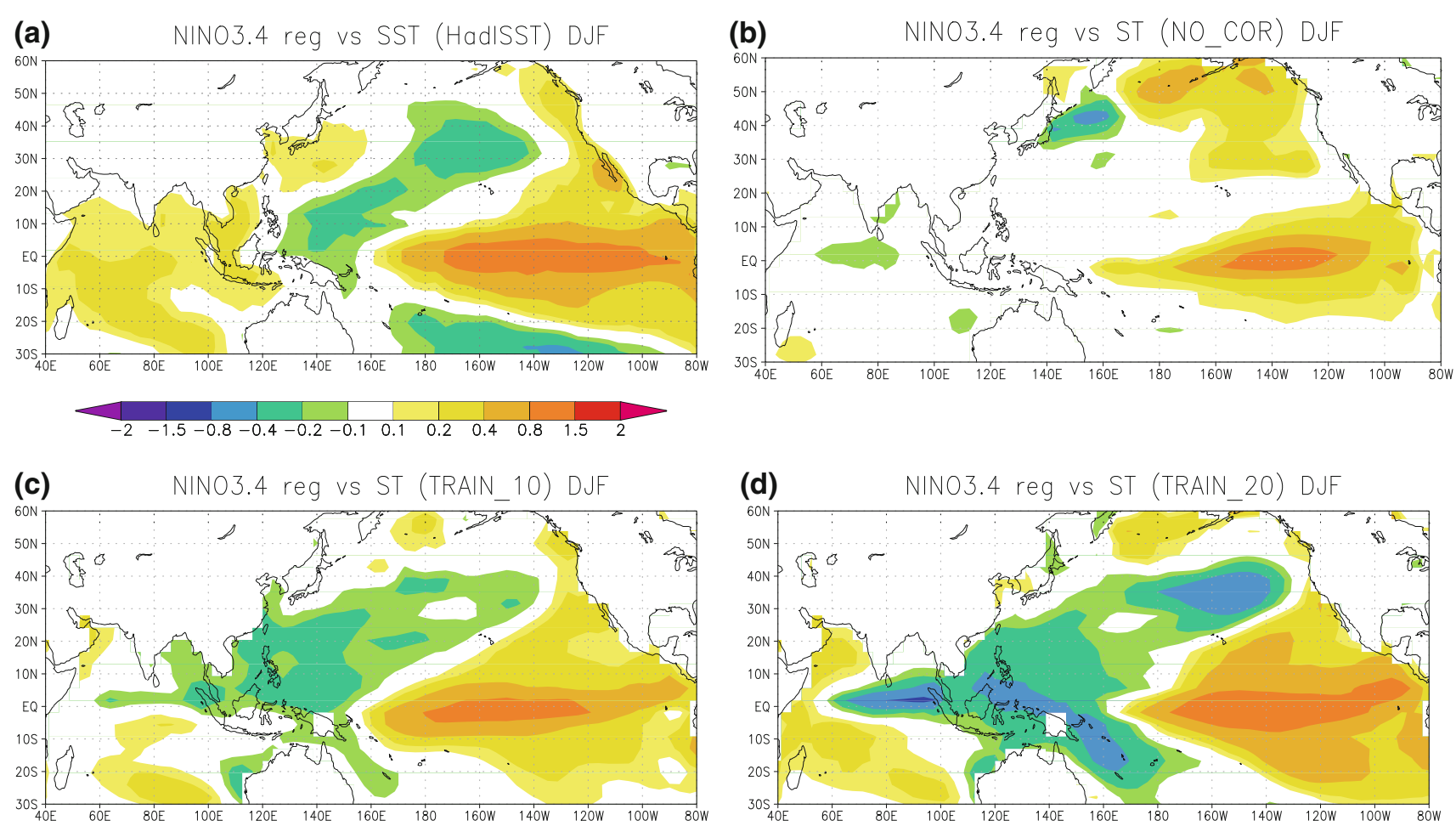

(e) NIN03.4 reg vS ST (TRAIN_30) DJF

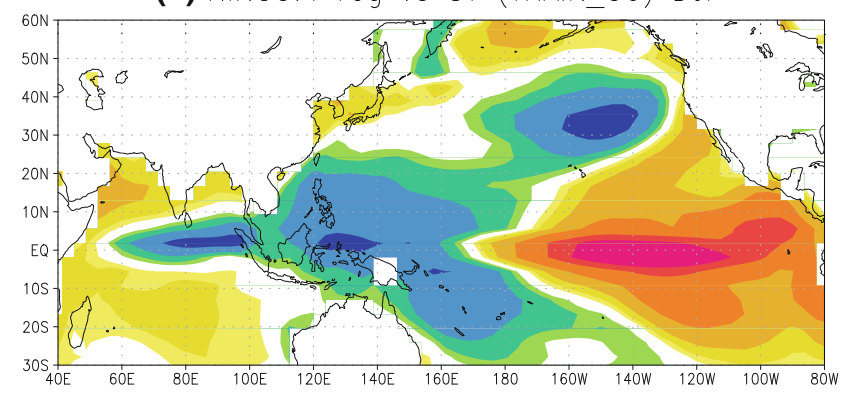

Fig. 8 Distribution of regression coefficients of SSTs onto the Nino3.4 index (model years 2050-2150): a HadISST (1950-2002), b NO_COR, c TRAIN_10, d TRAIN_20, e TRAIN_30. The units are ${ }^{\circ} \mathrm{C}$

Nino3.4 index. The observations (Fig. 9a) reveal the well known enhancement in precipitation in the central equatorial Pacific that is accompanied by a westerly wind anomaly, both being a necessary part of the positive Bjerknes feedback on ENSO (Bjerknes 1969).

NO_COR (Fig. 9b), in comparison with the observations, shows very weak regressions of the modeled variability in the Nino3.4 region with both the precipitation and the wind field, especially on the equator. Because of the much too cold background state in the equatorial Pacific, NO_COR is unable to establish significant ENSO variability (cf. Sect. 4.1) and, therefore, does not reveal the characteristic patterns of anomalous precipitation and wind that are essential ingredients to the ENSO phenomenon. The response in TRAIN_10 (Fig. 9c) is already much stronger than in NO_COR, but the anomalies are shifted to the western Pacific. This is partially due to the westward shift of the ENSO variability (see Fig. 8c) and partially due to the enhanced drift of mean SST in the equatorial eastern Pacific (see Fig. 3), leading to a stronger cooling in that area. TRAIN_20 (Fig. 9d) probably reveals the best agreement with observations. The strength and position of precipitation and winds strikingly match with the observations, even in the extratropical North Pacific. In TRAIN_30 (Fig. 9e) the regression analysis results in stronger amplitudes than in the observations and the maximum in precipitation is shifted to the east.

A further comparison of the observed wind and precipitation response to ENSO with SPEEDY stand-alone (forced with HadISST from 1950 to 2002), reveals spurious precipitation in the eastern tropical Indian Ocean and the western tropical Pacific and a too weak zonal wind response 
(a) NIN03.4 wind +prec (HadISST, NCEP, CMAP) DJ
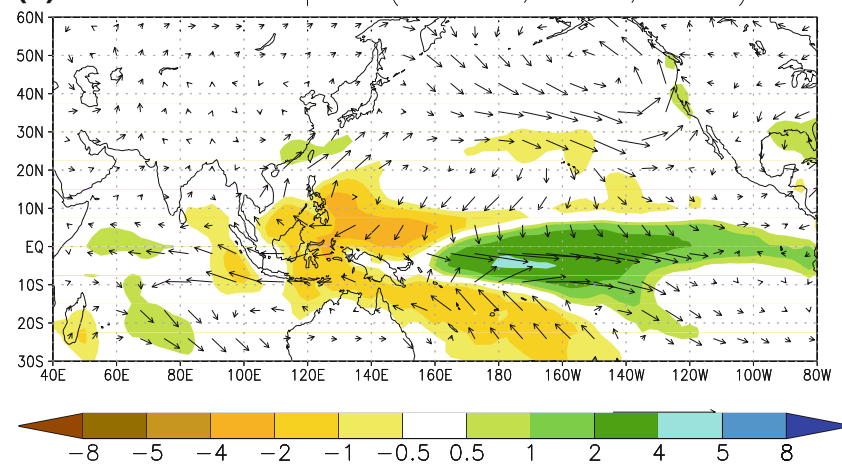

(c)

NIN03.4 wind+prec (TRAIN_10) DJF

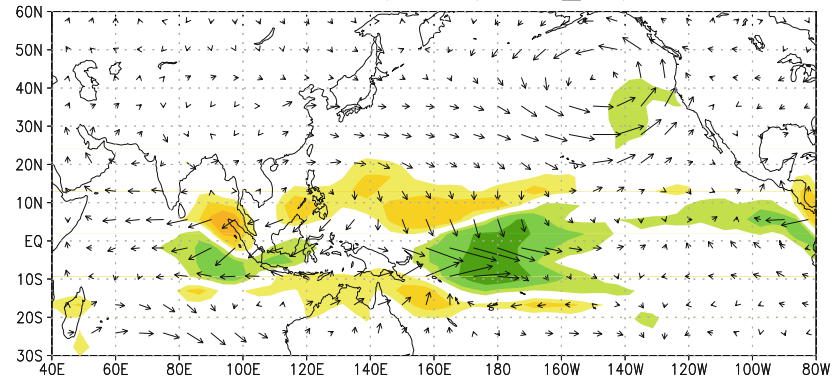

(e) NIN03.4 wind +prec (TRAIN_30) DJF

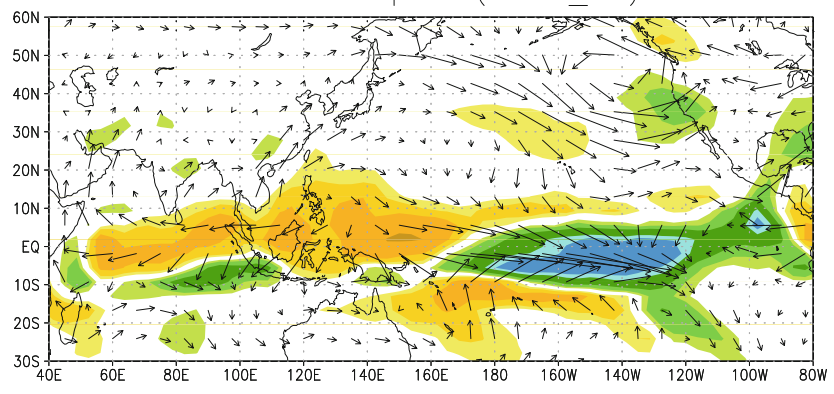

Fig. 9 Distribution of regression coefficients of precipitation and wind onto the Nino3.4 index (model years 2050-2150): a CMAP (precipitation, 1980-1998), NCEP/NCAR (925 hPa winds, 19502002), and Nino3.4 index from HadISST, b NO_COR, c TRAIN_10,

to ENSO in the central tropical Pacific (Fig. 9f), indicative of low sensitivity of the atmospheric model with respect to ocean forcing. The fact that our CGCM reveals the best connection between ocean and atmosphere in TRAIN_20, although the Nino3.4 amplitude is already considerably larger than the observed one (SD 1.28 vs. 0.74/0.81) corroborates the idea of the low sensitivity in SPEEDY. Apparently, the atmospheric component of our coupled system shows a realistic response to ENSO variability only when being forced by a vigorous SST signal. All the models in the intercomparison project of Davey et al. (2002) that exhibit a SD in SST in the Nino3 region $\left(150^{\circ}-90^{\circ} \mathrm{W}\right.$ and $5^{\circ} \mathrm{S}-5^{\circ} \mathrm{N}$ ) that is close to or higher than the observations (b) NINO3.4 wind+prec (NO_COR) DJF

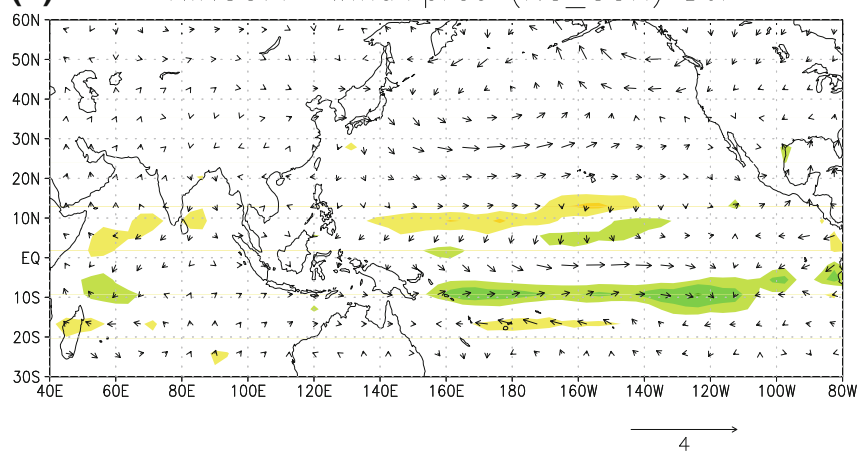

(d)

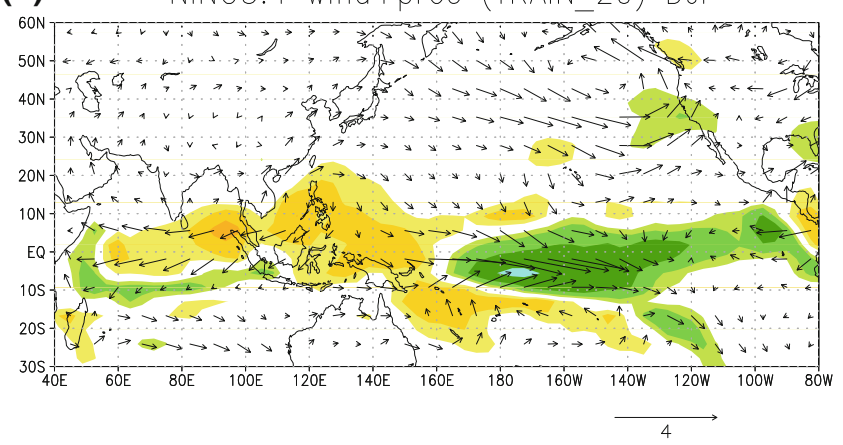

(f) NINO3.4 wind +prec (OBS_FORC) DJF

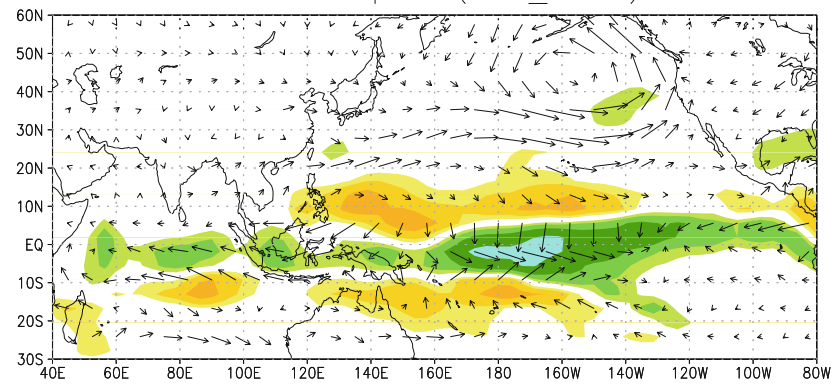

d TRAIN_20, e TRAIN_30, and f SPEEDY stand-alone forced with HadISST (1950-2002). The units are $\mathrm{mm} /$ day for precipitation and $\mathrm{m} / \mathrm{s}$ for wind

exhibit low atmospheric sensitivity. The models reveal ratios of interannual variability $(\mathrm{SD})$ between wind stress in the central equatorial Pacific and Nino3 SST that are substantially lower than those observed.

In order to better quantify the atmospheric response to ENSO variability in our experiments, we are considering the regression between SSTA in the ENSO region and the zonal wind stress in the central equatorial Pacific (spatial average from $160^{\circ} \mathrm{E}$ to $150^{\circ} \mathrm{W}$, Fig. 10). The connections of the wind stress to both the Nino3.4 and Nino3 indices are presented. Hereby, unlike in Figs. 8 and 9, regression coefficients are based on the covariance of the wind stress and the Nino index, normalized by the variance of the 
index (and not SD), as was done by Latif et al. (2001). This allows for a direct comparability of the atmospheric sensitivity among all experiments and the observations, regardless of the considerable range in the modeled SST variability in the ENSO region. In the observations (NCEP/ NCAR Re-analysis and HadISST), the maximum negative wind stress response to both the Nino3.4 and the Nino3 index is located close to the equator $\left(2^{\circ} \mathrm{S}\right)$ and exceeds $-0.01 \mathrm{~N} / \mathrm{m}^{2} /{ }^{\circ} \mathrm{C}$. Our model results coincide with the location of the maximum but reveal a wide spread regarding the amplitude. In any case (with both Nino3.4 and Nino3), a very weak negative wind stress of about -0.002 to $-0.003 \mathrm{~N} / \mathrm{m}^{2} /{ }^{\circ} \mathrm{C}$ can be found in the uncorrected run NO_COR (as expected from Fig. 9), whereas these values range from -0.008 to $-0.01 \mathrm{~N} / \mathrm{m}^{2} /{ }^{\circ} \mathrm{C}$ in the experiments with the adjustment applied. SPEEDY, when forced by the observations in stand-alone mode, shows a peak response to both Nino3.4 and Nino3 of about $-0.006 \mathrm{~N} / \mathrm{m}^{2} /{ }^{\circ} \mathrm{C}$ only.

When looking at the regression with the Nino3 index (the Nino3 index was also used for a similar diagnostic by Latif et al. 2001), all model runs with flux correction reveal the same peak atmospheric sensitivity about the equator that, furthermore, is equal to the one observed (Fig. 10, right). When looking at the regression with the Nino3.4 index (Fig. 10, left), on the other hand, the observed atmospheric sensitivity of about $-0.012 \mathrm{~N} / \mathrm{m}^{2} /{ }^{\circ} \mathrm{C}$ is not only higher than the observed response to the Nino3 SST variability but also exceeds the atmospheric sensitivity to the Nino3.4 forcing in all model runs. In TRAIN_10 and TRAIN_20, the response is weaker by more than $30 \%$ $\left(-0.008 \mathrm{~N} / \mathrm{m}^{2} /{ }^{\circ} \mathrm{C}\right)$, whereas it is closer to the observations in TRAIN_30 $\left(-0.01 \mathrm{~N} / \mathrm{m}^{2} /{ }^{\circ} \mathrm{C}\right)$. It is not surprising that TRAIN_30 shows the most realistic atmospheric sensitivity because the background state (as it is seen by the atmosphere) is closest to the observed one (cf. Fig. 3). It is

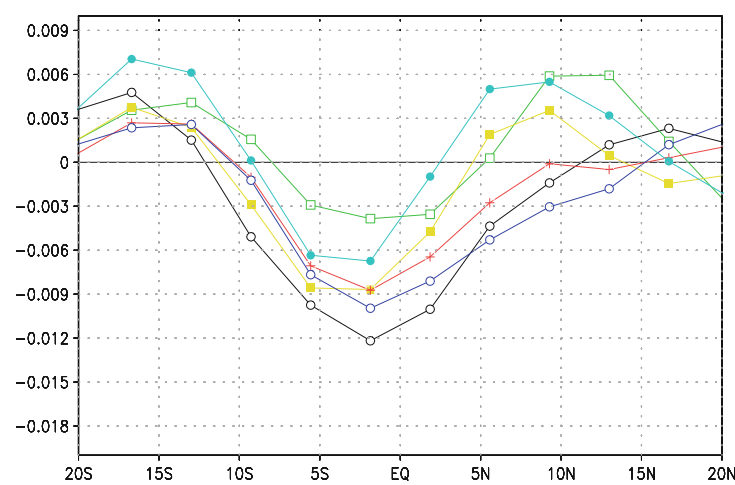

Fig. 10 Distribution of regression coefficients of (left) the Nino3.4 index and (right) the Nino3 index (averaged from $150^{\circ}-90^{\circ} \mathrm{W}$ to $5^{\circ} \mathrm{S}-$ $5^{\circ} \mathrm{N}$ ) onto the zonal wind stress, zonally averaged from $160^{\circ} \mathrm{E}$ to $150^{\circ} \mathrm{W}$ (model years 2050-2150): HadISST and NCEP/NCAR Re- surprising, on the other hand, that the SPEEDY stand-alone experiment that was subject to the observed background state reveals lower sensitivity. The set-up of SPEEDY is identical in both the coupled and the stand-alone mode. The weaker regression relation in the SST-prescribed simulation relative to the coupled model may simply be indicative of the difference between coupled and prescribed SST fields. Another possible reason for the decay in sensitivity could be the temporal resolution of the (HadISST) forcing field. In contrast to the coupled experiments that exchange fluxes once per day, the forcing of SPEEDY stand-alone is based on monthly mean fields. However, in our CGCM set-up, changes in atmospheric sensitivity are solely determined by changes in the background state. Given the high forcing frequency in all our coupled experiments, a background state that is close to the observed one leads to realistic atmospheric sensitivity.

Regarding the projection of the ENSO variability onto oceanic (SST) and atmospheric (precipitation, wind) properties, it appears that TRAIN_20 is our most realistic realization. The amplitude of the Nino3.4 index is already overestimated in TRAIN_20, but its effect on the precipitation and wind in the central equatorial basin is counterbalanced by the relatively weak atmospheric sensitivity in this run. In case of TRAIN_30, the excessive warm events in the Nino3.4 region, though more frequent, are not more pronounced. Given the more realistic atmospheric sensitivity in that run, the warm events indeed lead to a response in both precipitation and wind that is stronger than the observed response. The reason for the apparent contradiction of overestimated anomalies that are superimposed on a realistic (nowadays) SST climatology (that itself leads to realistic atmospheric sensitivity) has to be looked for in the ocean's thermocline structure.

In Fig. 11, the regression of equatorial temperatures in the upper $300 \mathrm{~m}$ on the Nino3.4 index is shown for all

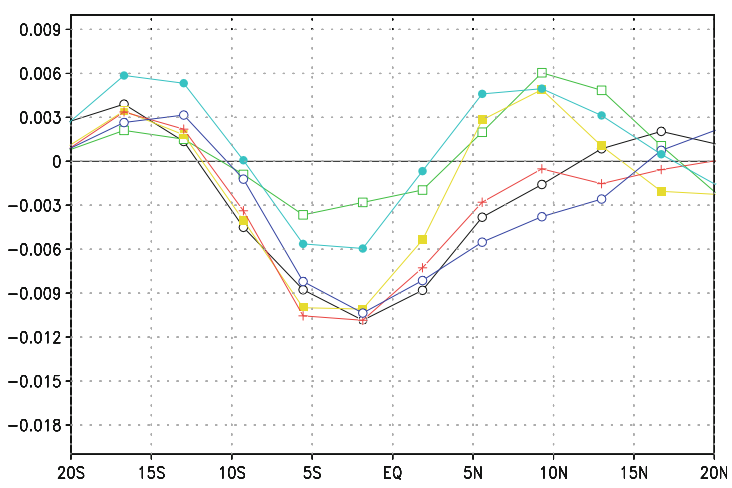

Analysis (1950-2002, black line), NO_COR (green), TRAIN_10 (yellow), TRAIN_20 (red) and TRAIN_30 (blue), and SPEEDY stand-alone forced with HadISST (1950-2002, light blue). The units are $\mathrm{N} / \mathrm{m}^{2} /{ }^{\circ} \mathrm{C}$ 

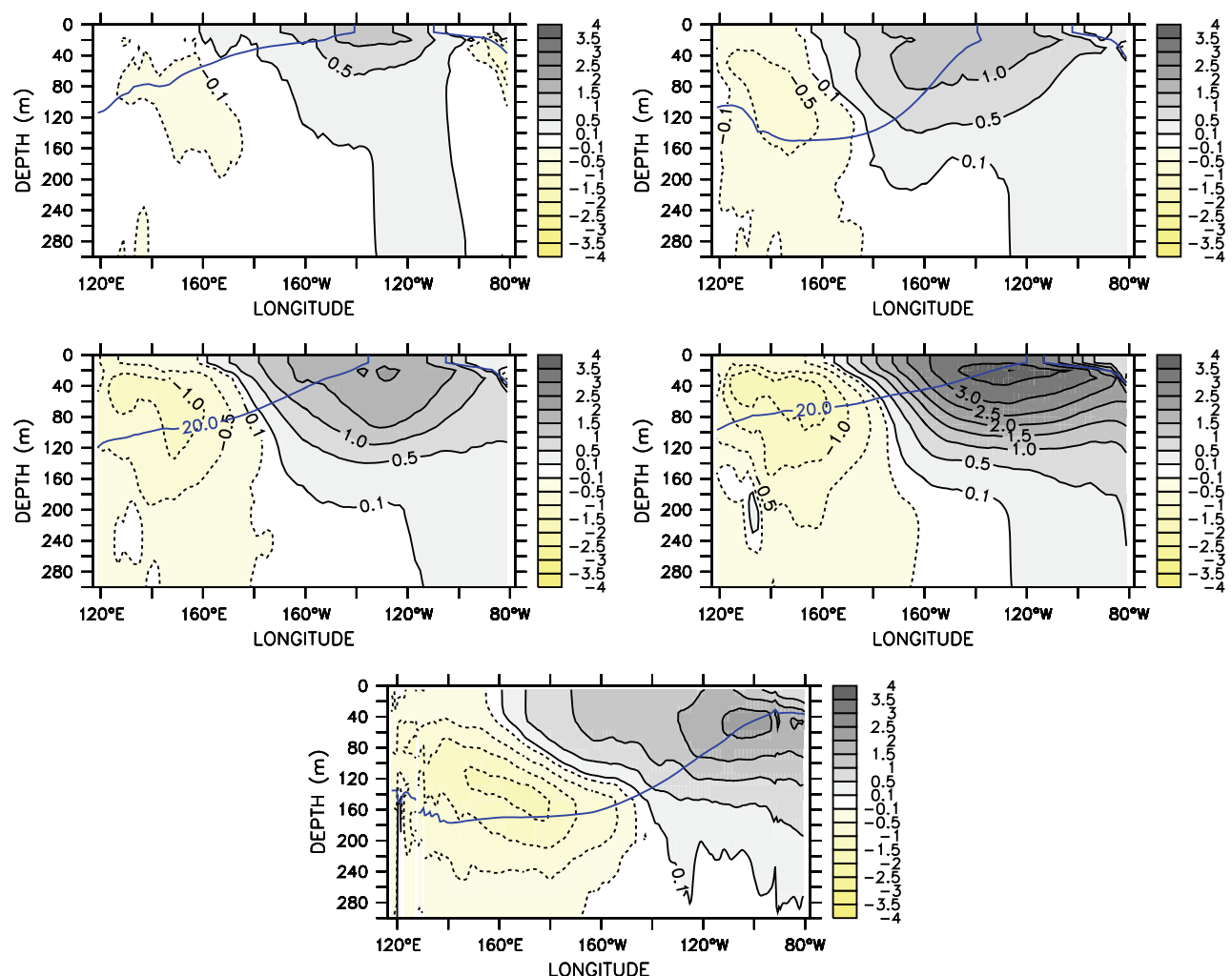

Fig. 11 Comparison of Nino3.4 regression on equatorial temperature (model years 2050-2150) in the experiments with (upper, left) no correction, (upper, right) 10 years, (center, left) 20 years, (center, right) 30 years of training, and in (lower) SODA (1958-2001) $\left({ }^{\circ} \mathrm{C}\right)$. Note the superimposed mean $20^{\circ} \mathrm{C}$ isotherm in blue

itself, they generally appear too shallow in the model. Temperature maxima in the east range from $1{ }^{\circ} \mathrm{C}$ in TRAIN_10 to $2^{\circ} \mathrm{C}$ in TRAIN_20 to $3.5^{\circ} \mathrm{C}$ in TRAIN_30 with $2^{\circ} \mathrm{C}$ in SODA. In the west we find $-1.5^{\circ} \mathrm{C}$ in SODA and $-0.5,-1,-1.5^{\circ} \mathrm{C}$ in TRAIN_10, TRAIN_20, TRAIN_30, respectively.

Besides being located too far west (around $130^{\circ} \mathrm{W}$ ) and too close to the surface (around $20-30 \mathrm{~m}$ depth), in TRAIN_20, the ENSO signal in the eastern half of the basin compares best with the observational maximum (around $100^{\circ} \mathrm{W}$ and $50 \mathrm{~m}$ ). The subsurface signal in the western half, located around $140^{\circ} \mathrm{E}$ and between 30 and $130 \mathrm{~m}$ (around $160^{\circ} \mathrm{E}$ and $140 \mathrm{~m}$ in SODA), appears slightly too low. In TRAIN_30, the pattern is very similar to the one in TRAIN_20. Here, the magnitude of the ENSO related signal in the western half of the basin matches the observations, but in the east the maximum amplitude is overestimated by a factor of almost 2 (again with a clear subsurface expression around 20 to $30 \mathrm{~m}$ ). Overall, with increasing correction the center of action is shifted from the Nino3.4 to the Nino3 region. The shoaling of the thermocline that we find in all our coupled runs increases ocean sensitivity and, hence, leads to enhanced SST variability. In TRAIN_30, the experiment with the most realistic atmospheric sensitivity, the enhanced ocean sensitivity results in 
both overestimated ENSO signals and overestimated ENSO projections on precipitation and wind in the atmosphere and on surface and subsurface temperatures in the tropical Pacific Ocean.

\subsection{Nino3.4 non-linearity and skewness}

Skewness, defined as the third standardized moment of the frequency distribution, provides a measure of the asymmetry in our ENSO time series. The distributions of warm and cold events depicted in histograms of the Nino3.4 index in Fig. 12 reveal enhanced asymmetry in the corrected experiments compared to observations and to the uncorrected run. The enhanced asymmetry is reflected in enhanced skewness (Table 1). The Nino3.4 index in NO_COR is not skewed at all (skewness 0.00), whereas the corrected runs reveal relatively high values, with the skewness increasing tremendously from TRAIN_10 (0.79) to TRAIN_20 (1.74) and its value lying between those experiments in TRAIN_30 (1.14). For comparison, the skewness of the Nino3.4 index in HadISST is $0.38(0.40)$ for the period 1871-2000 (1950-2000).

Since, in our interactive flux correction scheme, we do not account for the shallowing of the thermocline on the equator but do account for the cold bias at the surface (by adjusting toward warmer climatological SSTs), the corrected runs reveal an increased coupled sensitivity due to the following feedback loop. According to the ClausiusClapeyron relationship, the atmospheric response to SST anomalies becomes stronger with increasing background surface temperatures which in our model is accomplished
Table 1 Nino3.4 index: standard deviation (SD), skewness and period for the years 2071-2200 in the model and 1950-2000 (18712000) in the observations

\begin{tabular}{llll}
\hline Experiment & SD & Skewness & Oscillation period \\
\hline NO_COR & 0.68 & 0.00 & None \\
TRAIN_10 & 1.08 & 0.79 & $2-3$ \\
TRAIN_20 & 1.28 & 1.74 & $6-8$ \\
TRAIN_30 & 1.88 & 1.14 & $6-8$ \\
HadISST & $0.81(0.74)$ & $0.40(0.38)$ & $4-5$ \\
\hline
\end{tabular}

by the increasing bias correction from TRAIN_10 to TRAIN_30. At the same time, the cooled-down ocean-as opposed to the atmosphere, the ocean is subject to the full extent of the residual drift in the corrected system-with its shallow thermocline is highly sensitive to changes in the atmospheric wind forcing. The combination of both overall enhanced ocean sensitivity and the enforced increase of atmospheric sensitivity is reflected in enhanced coupled sensitivity in our flux corrected system.

In order to better understand the coupled sensitivity in our experiments we present scatter plots that describe the relation between SST in the Nino3.4 region and zonal wind stress in the central Pacific (Fig. 13, upper), and between the same SST and equatorial thermocline depth slightly further east in the Nino3 region (Fig. 13, lower). Note that deviations from the seasonal cycle are plotted for experiments NO_COR (green), TRAIN_10 (black) and TRAIN_30 (red). TRAIN_20 looks similar to TRAIN_30 and was omitted in the figures for clarity. In the corrected runs non-linear relationships are indicated between ENSO
Fig. 12 Histogram for model years 2050-2181 of Nino3.4 index: a HadISST (1871-2002), b NO_COR, c TRAIN_10, d TRAIN_20, e TRAIN_30
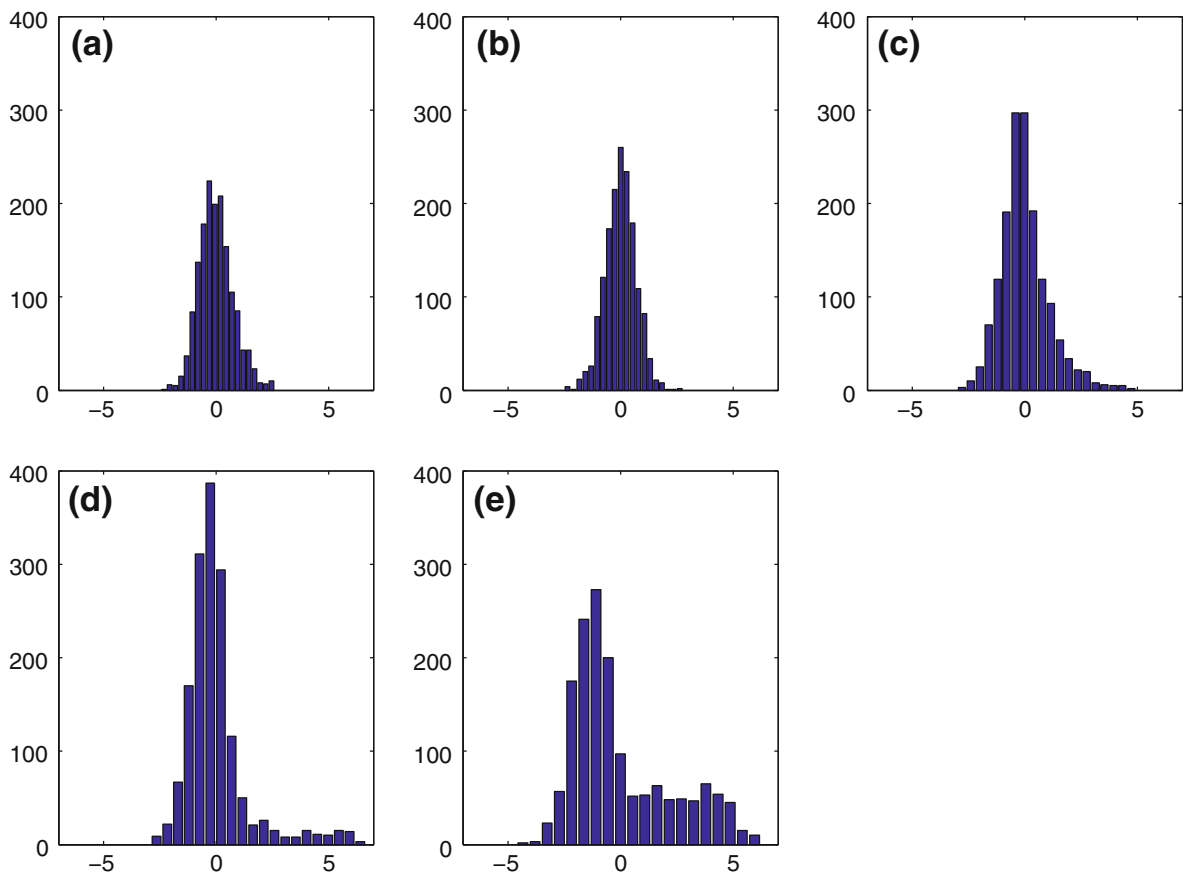
SST and changes in both atmospheric winds (TRAIN_10 and TRAIN_30) and thermocline depths in the ocean (TRAIN_30). These relationships in the uncorrected run are linear to first order. In NO_COR, SST deviations (about a cold background state of $24.1^{\circ} \mathrm{C}$ ) range from -2 to $2^{\circ} \mathrm{C}$ and coincide with about 0.01 to $-0.01 \mathrm{~N} / \mathrm{m}^{2}$ in zonal wind stress and -10 to $10 \mathrm{~m}$ in thermocline depth. The rates of change can be estimated to about $-0.0025 \mathrm{~N} / \mathrm{m}^{2} /{ }^{\circ} \mathrm{C}$ and $4 \mathrm{~m} /{ }^{\circ} \mathrm{C}$. The gradient of zonal wind stress is perfectly in line with the findings in Sect. 4.2 (Fig. 10).

The corrected runs shown in Fig. 13 (with the warmer background states of 25.6 and $27.5^{\circ} \mathrm{C}$ ) reveal enhanced atmospheric sensitivity already when regarding the wind response to moderate El Nino and La Nina events. This sensitivity further increases when looking into the region of
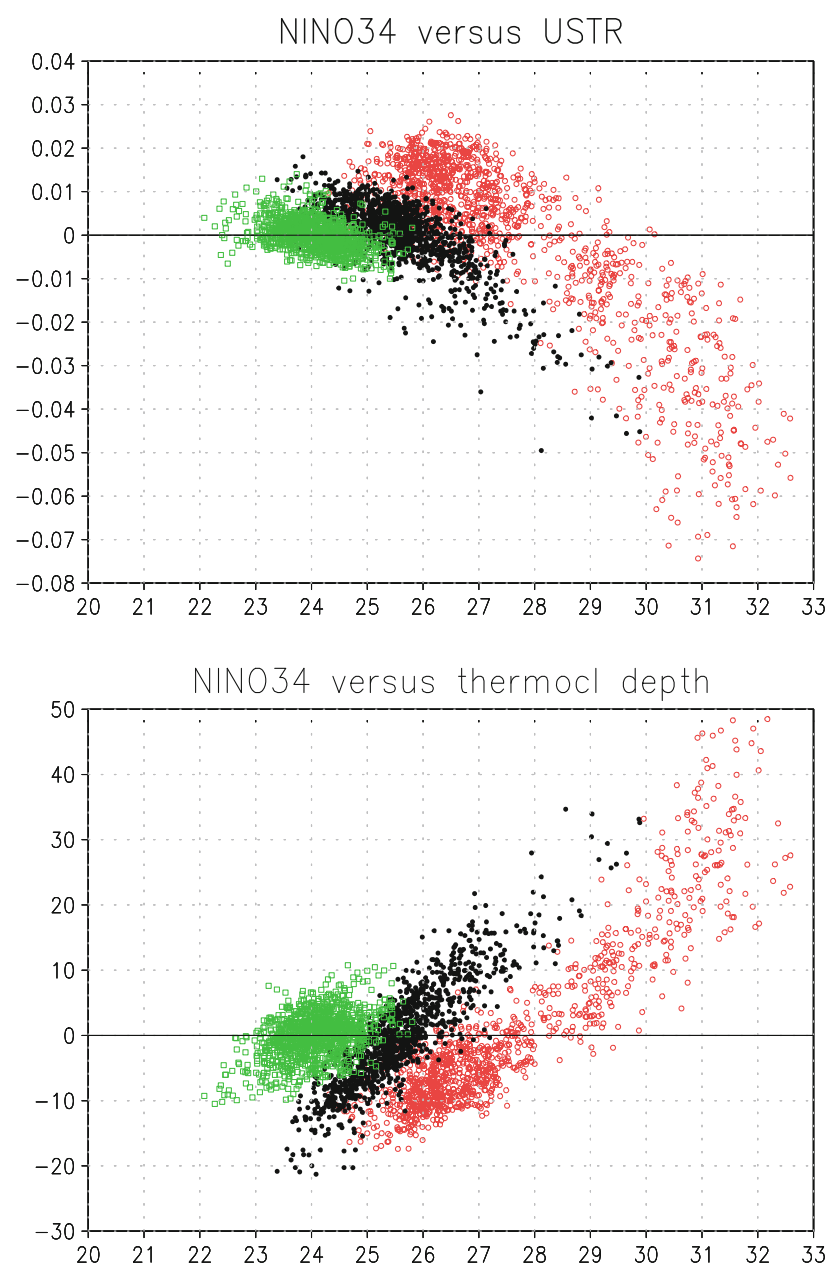

Fig. 13 Scatter plot for model years 2050-2150 of SST in the Nino3.4 region $\left({ }^{\circ} \mathrm{C}\right)$ and (upper) anomalous zonal wind stress, averaged from $160^{\circ} \mathrm{E}$ to $150^{\circ} \mathrm{W}$ and $5^{\circ} \mathrm{S}$ to $5^{\circ} \mathrm{N}\left(\mathrm{N} / \mathrm{m}^{2}\right)$ and (lower) depth anomalies of the ocean model layer $8\left(\sigma_{\theta} 25.77\right)$ as a proxy for the thermocline, averaged over the Nino3 region $(\mathrm{m})$ : (green) NO_COR, (black) TRAIN_10, (red) TRAIN_30. Note that all properties are deviations from the seasonal cycle (in case of SST the anomalous seasonal cycle was taken out) strong warm events with estimated maximum rates of change exceeding about $-0.015 \mathrm{~N} / \mathrm{m}^{2} /{ }^{\circ} \mathrm{C}$. The flux adjustment leads to an enhancement of the atmospheric sensitivity that is clearly of non-linear nature and reflected in the increasing skewness in the corrected runs. All our experiments are characterized by a shallow mean equatorial thermocline in the east. Here, subtle changes in thermocline depth due to subtle changes in the wind forcing lead to a strong response in surface temperatures. In the range of moderate warm and cold ENSO events, the ocean's sensitivity in terms of SST response to thermocline variability appears very similar in TRAIN_30 and NO_COR and somewhat weaker in TRAIN_10. The weaker response indicates that structural characteristics of the thermocline as, for example, the sharpness or the tilt (cf. Fig. 11) may also play a role for the ocean's sensitivity. When only looking at strong El Niños, that is, when the thermocline is relatively deep, the ocean's sensitivity in TRAIN_30 is effectively weakened and counteracts to some extent the increase in atmospheric sensitivity. Overall, given the relatively high ocean sensitivity in all experiments, only by increasing the atmospheric sensitivity via enforcing the warmer background states in the corrected runs is our system able to establish non-linear ENSO variability that is expressed in relatively high values of skewness.

Although our particular flux correction approach, by means of the intrinsic restoring mechanism that enhances (reduces) the net downward heat flux when surface temperatures tend to get too cold (too warm) (Sect. 2.2), is able to moderate the drift in the model, it is not able to prevent a substantial shoaling of the thermocline. Other processes seem to supersede the restoring effect of the heat flux. In order to understand what role the wind forcing in the CGCM plays for the thermocline drift, we have performed a sensitivity experiment based on TRAIN_20 where actual model winds were overwritten by observed (NCEP) winds before forcing the ocean (in coupled mode). The altered feedback into the ocean (based on "realistic" winds), which was the only difference in the set-up as compared to TRAIN_20, resulted in a similar degraded thermocline structure and, therefore, appeared not to be efficient in stopping the thermocline from migrating towards the surface (not shown). This strongly suggests that in our coupled system the reason for the drift in the ocean has to be looked for in the ocean.

\subsection{Lagged Nino3.4 regressions}

The 1976/1977 "climate shift" debate and its influence on ENSO properties has been discussed intensely in the recent scientific literature (e.g., Zhang et al. 1997; D'Arrigo et al. 2005; Wu et al. 2005; Ye and Hsieh 2006). One of the characteristics of ENSO that experienced a change during the climate shift is the propagation of ENSO-preceding 
SST anomalies that are known to be mainly westward before and eastward after 1976/1977 (e.g.,Wang and Picaut 2004; Guilyardi 2005).

These two modes are termed SST mode (S-mode) and thermocline mode (T-mode), respectively (e.g., Fedorov and Philander 2001; Guilyardi 2005). In reality, the coupled ocean-atmosphere modes are hybrids of the T- and Smode (e.g., Neelin et al. 1998; Fedorov and Philander 2000). Based on their stability analysis by means of a Zebiak-Cane-type model (Zebiak and Cane 1987), Fedorov and Philander (2001) explored the characteristics of the unstable T- and S-mode: The S-mode has a shorter period than the T-mode and does not involve thermocline variability. In the S-mode, SST variations in the ENSO region depend on upwelling and advection induced by local wind fluctuations. In the T-mode, on the other hand, the SST variability is mainly driven by vertical movements of the thermocline in response to wind fluctuations farther west. In the T-mode, the structures of the evolution of SST and thermocline depth anomalies along the equator resemble the structures of both the delayed oscillator mode (Suarez and Schopf 1988; Battisti 1988) (see Battisti and Hirst 1989) and the recharge oscillator mode (Jin 1997a, b).
One way to analyze ENSO related equatorial propagation properties is to calculate lagged correlations along the equator between the Nino3.4 index and the variable of interest. First, we look at SST (averaged from $5^{\circ} \mathrm{S}$ to $5^{\circ} \mathrm{N}$ ). Figure 14a and $\mathrm{b}$ show the results for the HadISST data before and after the 1976/1977 climate shift. Eastward propagation from the central Pacific into the eastern basin (T-mode) can easily be identified for the time after 1976/ 1977 (Fig. 14b); the opposite westward propagation (Smode) before 1976/1977 is somewhat less obvious but still detectable by a slight tilt of the eastern Pacific anomaly at short negative lags (Fig. 14a). The eastward propagation in Fig. $14 \mathrm{~b}$ can be traced back to about 1 year (lag -12 months) before the ENSO event (lag 0). Prior to one year it is difficult to distinguish the propagation from the previous ENSO teleconnection into the central Pacific (cf. at lag -18 months). Furthermore, an increase of the period of the ENSO oscillation is evident between Fig. 14a and b, that is, after the climate shift in 1976/1977.

Regarding the T- and S-mode, we can identify very diverse behavior in our coupled runs. NO_COR (Fig. 14c) does not reveal an oscillatory character at all (as already discussed in Sect. 4.1). TRAIN_10 shows no clear
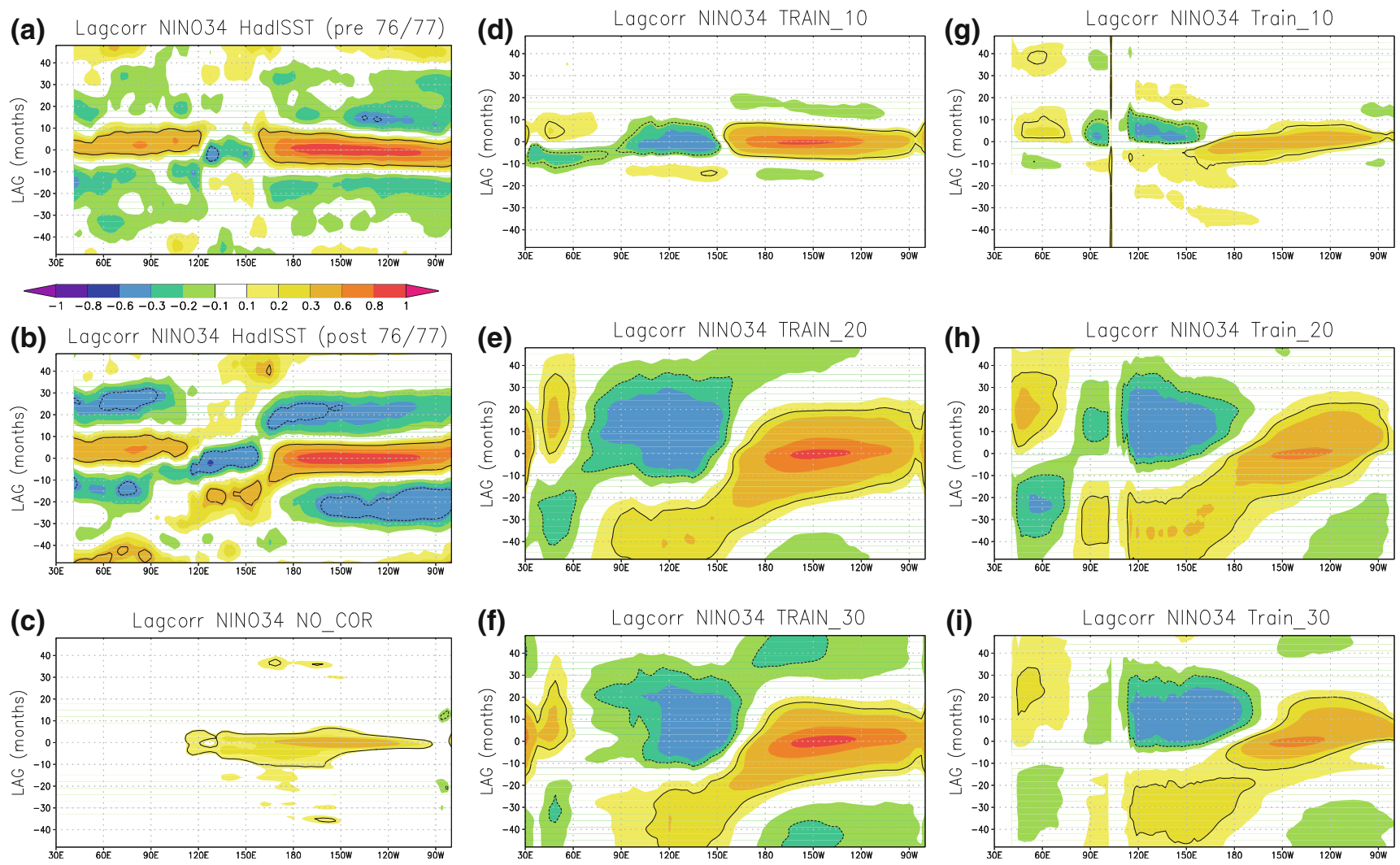

Fig. 14 Lagged correlation (model years 2050-2150) between the Nino3.4 index and (left and middle column) SSTs and (right column) ocean model layer $8\left(\sigma_{\theta} 25.77\right)$ as a proxy for thermocline variability (contour lines indicate significance levels at $90 \%$ based on a $t$ test): a HadISST (1950-1976), b HadISST (1977-2002), c NO_COR, d TRAIN_10, e TRAIN_20, $\mathbf{f}$ TRAIN_30, $\mathbf{g}$ TRAIN_10, h TRAIN_20, i TRAIN_30 
propagation of the SST anomalies and resembles more the S-mode-type behavior in the observations before 1976/ 1977 (Fig. 14d). On the other hand, TRAIN_20 (Fig. 14e) and TRAIN_30 (Fig. 14f) clearly reveal eastward propagation of the SST signal, that, with a propagation time scale of about 2-3 years (lags around -30 ), reflects the overestimated ENSO periods in those runs. Together with the apparent shift from S- to T-mode in our corrected runs and the accompanying shift to longer time scales of the ENSO cycle, we find an eastward shift of the ENSO related zonal wind stress anomaly pattern from TRAIN_10 to TRAIN_20 and TRAIN_30 (Fig. 9). An and Wang (2000) have reported an eastward shift of the zonal wind stress anomaly pattern related to ENSO to be the primary structural change of the coupled mode after the climate shift.

The ENSO time scales in TRAIN_20 and TRAIN_30, with 6-8 years (cf. Sect. 4.1) are unrealistically large and seem to be a consequence of our flux adjustment procedure. According to the delayed oscillator model, the accumulating restoring effect of successive equatorial Rossby and reflected Kelvin wave events in the central and western Pacific is required to work against the positive Bjerknes feedback in the eastern basin, which itself excites the ocean wave processes via the zonal wind stress anomaly in the central Pacific. (e. g. Cane et al. 1990,..."constant dripping wears away the stone"). The stronger the Bjerknes coupling the more wave processes are needed for the transition from a warm into a cold ENSO phase. The enhanced adjustment towards warmer climate states in TRAIN_20 and TRAIN_30 favors strong coupling and leads to the build up of extreme warm events of $O\left(5-6^{\circ} \mathrm{C}\right)$ (cf. 4.1). We hypothesize that the extended ENSO time scales in TRAIN_20 and TRAIN_30 can be explained by the strong coupling in these experiments that requires a substantial amount of successive wave processes in order to tip ENSO into its cold state.

In all corrected runs, ENSO-induced eastward propagating thermocline anomalies can be identified over the entire Pacific basin (Fig. 14g-i), which in TRAIN_20 and TRAIN_30 bear a striking resemblance to the SST signal (Fig. 14e, f). The thermocline in TRAIN_10, in contrast to experiments TRAIN_20 and TRAIN_30, appears too deep in the west Pacific for allowing a connection of the transient thermocline signals to the surface. In the observational estimate from SODA, a moderate shoaling of the equatorial thermocline (of about $20 \mathrm{~m}$ ) in the west Pacific (not shown) coincides with the change into the T-mode after the climate shift, which, though less pronounced, is in line with our model results. Nevertheless, the eastward propagating thermocline signal in TRAIN_10 is indicative of an inherent T-mode also in that experiment. Given the Smode characteristics of other properties in TRAIN_10, such as no apparent SST propagation to the east, a short
ENSO period or the ENSO-related zonal wind stress anomaly pattern being located too far to the west, the ENSO mode in TRAIN_10 has rather to be regarded as a hybrid mode.

\section{Summary and discussion}

We have introduced a new interactive flux correction scheme and studied its impact on ENSO characteristics in a fast CGCM. Each time the coupled system exchanges information at the ocean-atmosphere interface, the computation of heat fluxes is performed twice, and a correction is applied to oceanic SST. Only fluxes seen by the atmosphere are modified by the corrected SST in order to prevent the atmosphere from responding to potential drift in the ocean state. The modified fluxes are based on anomalies of SST (SSTA) that are superimposed on an observed climatology. The calculation of SSTA requires knowledge of the model's climatological SST field which is determined iteratively during spin-up of the coupled system ("training"). During the training period, the climatology is recalculated every year and is also applied after the first training year to the heat flux calculation for the atmosphere. The calculations of the evolving climatology and of the corrected fluxes are interdependent. A suite of experiments has been performed that differ in the length of the training period (10, 20, 30 years, and continuous).

The interactive flux adjustment strategy, by simply counteracting the SST drift in the model, allows sufficient atmospheric sensitivity in our CGCM for the generation of ENSO-type variability. All flux corrected simulations contain various characteristics of the ENSO phenomenon that are poorly represented by the uncorrected CGCM. Between the three implementations of the flux correction, which are distinguished only by different durations of training, we find very different Nino3.4 indices that range from realistic amplitudes with periods of $2-3$ years to stronger-than-observed amplitudes with periods of 6-8 years. Strong and warm El Niño events prevail in all corrected runs, which is indicative of the non-linear nature of these realizations and reflected by high values of skewness. In contrast, the uncorrected run is neither skewed nor contains an ENSO-type oscillatory behavior. Furthermore, when compared to observations, the runs with 20 and 30 years of training show a realistic phase locking of the Nino3.4 variability, despite the fact that their SDs are generally too high because of strong warm events.

The regressions of oceanic (SST, equatorial temperature) and atmospheric (precipitation, wind) properties on the Nino3.4 index reveal remarkable improvements regarding ENSO teleconnections and ocean-atmosphere coupling in the corrected runs. The spatial patterns and 
magnitudes of ENSO-induced wind and precipitation are very close between the experiment with 20 years training and an observational estimate. In this realization, the overestimated amplitude of the Nino3.4 index is counterbalanced by too weak atmospheric sensitivity to the ocean forcing. The ENSO-induced wind and precipitation signals in the experiment with 30 years training are too strong. Here, the Nino3.4 index is also overestimated but the atmospheric sensitivity to the ocean forcing is more realistic.

The appearance of overly strong El Niño events in all corrected runs is based on shoaling of the thermocline in the ENSO region, which is responsible for a higher sensitivity of the ocean to atmospheric wind forcing. Unlike the surface ocean background state seen by the atmosphere, the drift to colder temperatures in surface and subsurface layers of the ocean's cold tongue region is not directly affected by the flux correction scheme. Therefore, the scheme is not able to prevent the thermocline from migrating upward. Overall, the flux correction enhances the coupled sensitivity in the CGCM and the skewness of the SST distribution in the El Niño region, both of which were not sufficiently represented in the uncorrected model. But, it is also apparent that the magnitudes of these properties are too large compared to observational estimates. Improvement of the depth of the thermocline and its sharpness, which may also play an important role for ENSO in the coupled model, will be subject to future research.

Along the equator, the experiments with 20 and 30 years of training show lagged SST correlations with ENSO that are reminiscent of the eastward SST propagation observed after the 1976/1977 "climate shift". The SST signals that precede ENSO in the experiment with only 10 years of training, on the other hand, are similar to the observations before the climate shift. These structural changes are associated with a mode switch of the ENSO phenomenon, with the "SST mode" prevailing before the climate shift and the "thermocline mode" thereafter. In the experiment with 10 years of training, the idea of a prevailing SST mode is corroborated by the relatively high frequency of ENSO variability and by an ENSO-related zonal wind stress anomaly located too far to the west. Lagged correlation of thermocline depth with ENSO in all corrected runs, on the other hand, shows eastward propagation and is strongly suggestive of the thermocline mode. In summary, with longer training durations we observe a switch in our model from a mixed or hybrid ENSO mode to a thermocline ENSO mode, a switch that closely resembles the observed mode switch that is associated with the climate shift.

Acknowledgments We thank Franco Molteni for motivating the interactive flux correction scheme and for helpful discussions during all stages of the work. In addition, we thank David DeWitt, Zoltan
Szüts, and two anonymous reviewers for many helpful comments on the manuscript. The experiments in this article were performed as a contribution to the ENSEMBLES project funded by the European Commissions 6th Framework Programme, contract number GOCECT-2003-505539.

Open Access This article is distributed under the terms of the Creative Commons Attribution Noncommercial License which permits any noncommercial use, distribution, and reproduction in any medium, provided the original author(s) and source are credited.

\section{References}

AchutaRao K, Sperber KR (2006) ENSO simulation in coupled ocean-atmosphere models: are the current models better? Clim Dyn 27:1-15. doi:10.1007/s00382-006-0119-7

An SI, Kang IS (2000) A further investigation of the recharge oscillator paradigm for ENSO using a simple coupled model with the zonal mean and eddy separated. J Clim 13:1987-1993

An SI, Wang B (2000) Interdecadal change of the structure of the ENSO mode and its impact on the ENSO frequency. J Clim 13:2044-2055

Battisti DS (1988) Dynamics and thermodynamics of a warming event in a coupled tropical atmosphere-ocean model. J Atmos Sci 45:2889-2919

Battisti DS, Hirst AC (1989) Interannual variability in a tropical atmosphere-ocean model: influence of the basic state, ocean geometry and nonlinearity. J Atmos Sci 46:1687-1712

Bjerknes J (1969) Atmospheric teleconnections from the equatorial Pacific. Mon Weather Rev 97(3):163-172

Bleck R, Rooth C, Hu D, Smith LT (1992) Salinity-driven thermocline transients in a wind- and thermohaline-forced isopycnic coordinate model of the North Atlantic. J Phys Oceanogr 22:1486-1505

Bracco A, Kucharski F, Kallummal R, Molteni F (2004) Internal variability, external forcing and climate trends in multi-decadal AGCM ensembles. Clim Dyn 23:659-678. doi:10.1007/s00382004-0465-2

Bracco A, Kucharski F, Molteni F, Hazeleger W, Severijns C (2005) Internal and forced modes of variability in the Indian Ocean. Geophys Res Lett 32:L12707 doi:10.1029/2005GL023154

Bracco A, Kucharski F, Molteni F, Hazeleger W, Severijns C (2006) A recipe for simulating the interannual variability of the Asian Summer Monsoon and its relation with ENSO. Clim Dyn. doi: 10.1007/s00382-006-0190-0

Cane MA, Münnich M, Zebiak SE (1990) A study of self-excited oscillations of the tropical ocean-atmosphere system. Part I: linear analysis.J Atmos Sci 47(13):1562-1577

Carton J, Chepurin G, Cao X, Giese B (2000) A simple ocean data assimilation analysis of the global upper ocean 1950-95. Part I: methodology. J Phys Oceanogr 30:294-309

D'Arrigo R, Wilson R, Deser C, Wiles G, Cook E, Villalba R, Tudhope A, Cole J, Linsley B (2005) Tropical-North Pacific climate linkages over the past four centuries. J Clim 18:52535265

Davey MK, Huddleston M et al (2002) STOIC: a study of coupled model climatology and variability in tropical ocean regions. Clim Dyn 18:403-420. doi:10.1007/s00382-001-0188-6

Fedorov AV, Philander SG (2000) Is El Niño changing? Science 288:1997-2002

Fedorov AV, Philander SG (2001) A stability analysis of tropical ocean-atmosphere interactions: bridging measurements and theory for El Niño. J Clim 14:3086-3101 
Guilyardi E (2005) El Niño-mean state—seasonal cycle interactions in a multi-model ensemble. Clim Dyn. doi:10.1007/s00382-0050084-6

Haarsma RJ, Campos EJD, Hazeleger W, Piola AR, Molteni F (2005) Dominant modes of variability in the South Atlantic: a study with a hierarchy of ocean-atmosphere models. J Clim 18:17191735

Hazeleger W, Haarsma R (2005) Sensitivity of tropical Atlantic climate to mixing in a coupled ocean-atmosphere model. Clim Dyn 25:387-399. doi:10.1007/s00382-005-0047-y

Hazeleger W, Severijns C, Haarsma R, Selten F, Sterl A (2003) SPEEDO-model description and validation of a flexible coupled model for climate studies. Technical report, KNMI, de Bilt, The Netherlands, TR-257, $37 \mathrm{pp}$

IPCC (2007) Climate Change 2007: the physical science basis. In: Solomon S, Qin D, Manning M, Chen Z, Marquis M, Averyt KB, Tignor M, Miller HL (eds) Contribution of Working Group I to the Fourth Assessment Report of the Intergovernmental Panel on Climate Change. Cambridge University Press, Cambridge, $996 \mathrm{pp}$

Ji M, Behringer DW, Leetmaa A (1998) An improved coupled model for ENSO prediction and implications for ocean initialization. Part II: the coupled model. Mon Weather Rev 126:1022-1034

Jin FF (1997a) An equatorial ocean recharge paradigm for ENSO. Part I: conceptual model. J Atmos Sci 54:811-829

Jin FF (1997b) An equatorial ocean recharge paradigm for ENSO. Part II: a stripped-down coupled model. J Atmos Sci 54:830-847

Kalnay E et al (1996) The NCEP/NCAR 40-year reanalysis project. Bull Am Meteorol Soc 77:437-471

Kirtman BP (1997) Oceanic Rossby wave dynamics and the ENSO period in a coupled model. J Clim 10:1690-1704

Kirtman BP (2003) The COLA anomaly coupled model: ensemble ENSO prediction. Mon Weather Rev 131:2324-2341

Kucharski F, Molteni F, Bracco A (2006) Decadal interactions between the western tropical Pacific and the North Atlantic Oscillation. Clim Dyn 26:79-91. doi:10.1007/s00382-005-0085-5

Kucharski F, Bracco A, Yoo JH, Molteni F (2007) Low-frequency variability of the Indian Monsoon-ENSO relation and the tropical Atlantic: the "weakening" of the 1980s and 1990s. J Clim 20:4255-4266

Kucharski F, Bracco A, Yoo JH, Molteni F (2008) Atlantic forced component of the Indian Monsoon interannual variability. Geophys Res Lett L04706. doi:10.1029/2007GL033037

Lambert SJ, Boer GJ (2001) CMIP1 evaluation and intercomparison of coupled climate models. Clim Dyn 17:83-106

Latif M, Sperber K et al. (2001) ENSIP: the El Niño simulation intercomparison project. Clim Dyn 18:255-276. doi:10.1007/ s00382-001-0188-6

Levitus S, Burgett R, Boyer TP (1994) World Ocean Atlas 1994, vol 3 salinity and vol 4 temperature. NOAA Atlas NESDIS 3, NOAA, Washington, DC
Macias J, Stephenson D, Kearsley A (1999) A basic reference state suitable for anomaly-coupled ocean-atmosphere climate models. Appl Math Lett 12:21-24

Manganello JV, Huang B (2009) The influence of systematic errors in the Southeast Pacific on ENSO variability and prediction in a coupled GCM. Clim Dyn 32:1015-1034. doi:10.1007/s00382008-0407-5

Molteni F (2003) Atmospheric simulations using a GCM with simplified physical parameterizations. I: model climatology and variability in multi-decadal experiments. Clim Dyn 20:175-191

Neelin JD, Battisti DS, Hirst AC, Jin FF, Wakata Y, Yamagata T, Zebiak SE (1998) ENSO theory. J Geophys Res 103(C7): $14,261-14,290$

Philander SG (1989) El Niño, La Niña, and the Southern Oscillation. Academic Press, New York

Rayner NA, Parker DB, Horton EB, Folland CK, Alexander LV, Rowell DP, Kent EC, Kaplan A (2003) Global analyses of sea surface temperature, sea ice, and night marine air temperature since the late nineteenth century. J Geophys Res 108:4407 doi: 10.1029/2002JD002670

Spencer H, Sutton R, Slingo JM (2007) El Niño in a coupled climate model: sensitivity to changes in mean state induced by heat flux and wind stress corrections. J Clim 20:2273-2298. doi:10.1175/ JCLI4111.1

Suarez MJ, Schopf PS (1988) A delayed action oscillator for ENSO. J Atmos Sci 45(21):3283-3287

Toniazzo T, Collins M, Brown J (2008) The variation of ENSO characteristics associated with atmospheric parameter perturbations in a coupled model. Clim Dyn 30:643-656. doi:10.1007/ s00382-007-0313-2

Wang C, Picaut J (2004) Understanding ENSO physics—a review. In: Earth's climate: the ocean-atmosphere interaction. Am Geophys Union Geogr Monogr 147:21-48. doi:10.1029/147GM01

Wang X, Jin FF, Wang Y (2003) A tropical ocean recharge mechanism for climate variability. Part II: a unified theory for decadal and ENSO modes. J Clim 16:3599-3616

Wu L, Lee DE, Zhengyu L (2005) The 1976/77 North Pacific climate regime shift: the role of subtropical ocean adjustment and coupled ocean-atmosphere feedbacks. J Clim 18:5125-5140

Xie P, Arkin PA (1997) Global precipitation: a 17-year monthly analysis based on gauge observations, satellite estimates, and numerical model outputs. Bull Am Meteorol Soc 78:2539-2558

Ye Z, Hsieh WW (2006) The influence of climate regime shift on ENSO. Clim Dyn 26:823-833. doi:10.1007/s00382-005-0105-5

Zebiak SE, Cane MA (1987) A model El Niño-Southern Oscillation. Mon Weather Rev 115(10):2262-2278

Zhang Y, Wallace JM, Battisti DS (1997) ENSO-like interdecadal variability: 1900-93. J Clim 10:1004-1020 